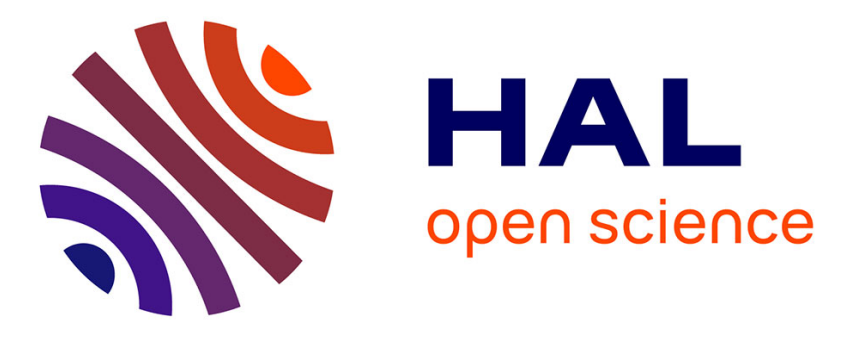

\title{
Dye removal by biosorption using cross-linked chitosan-based hydrogels
}

Grégorio Crini, Giangiacomo Torri, Eric Lichtfouse, George Z Kyzas, Lee D Wilson, Nadia Morin-Crini

\section{- To cite this version:}

Grégorio Crini, Giangiacomo Torri, Eric Lichtfouse, George Z Kyzas, Lee D Wilson, et al.. Dye removal by biosorption using cross-linked chitosan-based hydrogels. Environmental Chemistry Letters, 2019, 17 (4), pp.1645 - 1666. 10.1007/s10311-019-00903-y . hal-02402902

\section{HAL Id: hal-02402902 https://hal.science/hal-02402902}

Submitted on 10 Dec 2019

HAL is a multi-disciplinary open access archive for the deposit and dissemination of scientific research documents, whether they are published or not. The documents may come from teaching and research institutions in France or abroad, or from public or private research centers.
L'archive ouverte pluridisciplinaire HAL, est destinée au dépôt et à la diffusion de documents scientifiques de niveau recherche, publiés ou non, émanant des établissements d'enseignement et de recherche français ou étrangers, des laboratoires publics ou privés. 


\title{
Dye removal by biosorption using cross-linked chitosan-based hydrogels
}

\author{
Grégorio Crini $^{1}$ (1) $\cdot$ Giangiacomo Torri $^{2} \cdot$ Eric Lichtfouse $^{3}$ (1) $\cdot$ George Z. Kyzas ${ }^{4} \cdot$ Lee D. Wilson $^{5} \cdot$ Nadia Morin-Crini $^{1}$ (1)
}

\begin{abstract}
Synthetic dyes are an important class of recalcitrant organic compounds that are often found in the environment as a result of their wide industrial use. There are estimated to be more than 100,000 commercially available dyes. These substances are common contaminants, and many of them are known to be toxic or carcinogenic. Colored effluents from the industry is perceived by the public as an indication of the presence of a dangerous pollution. Even at very low concentrations, dyes are highly visible — an esthetic pollution — and modify the aquatic life and food chain, as a chemical contamination. Dye contamination of water is a major problem worldwide, and the treatment of wastewaters before their discharge into the environment has become a priority. Dyes are difficult to treat due to their complex aromatic structure and synthetic origin. In general, a combination of different physical, chemical and biological processes is often used to obtain the targeted water quality. Nonetheless, there is a need to develop new removal strategies and decolorization methods that are more effective, acceptable for industrial use and ecofriendly. Currently, there is increasing interest in the application of biological materials as effective adsorbents for dye removal. Among all the materials proposed, cross-linked chitosan-based hydrogels are the most popular biosorbents. These polymeric matrices are the object of numerous fundamental studies. In this review, after a brief description of the use of chitosan in wastewater treatment and the basic principles of chitosan-based hydrogels and biosorption, we focus on some of the work published over the past 5 years. Overall, these polymeric materials have demonstrated outstanding removal capabilities for some dyes. They might be promising biosorbents for environmental purposes.
\end{abstract}

Keywords Chitosan $\cdot$ Hydrogels $\cdot$ Dyes $\cdot$ Biosorption $\cdot$ Batch

\section{Introduction}

Water pollution by dyes remains a serious environmental and public problem (Sharma 2015; Khalaf 2016; MorinCrini and Crini 2017; de Andrade et al. 2018; Karimifard and Moghaddam 2018; Katheresan et al. 2018). Many industries such as chemicals, textiles, pulp and paper, metallurgy, leather, paint and coatings industry, food, packaging, pharmacy, and plastics consume considerable amounts of water and chemical reagents during processing, dyeing and finishing operations. Due to their high solubility, dyes are common water pollutants and may frequently be found in

\author{
Grégorio Crini \\ gregorio.crini@univ-fcomte.fr \\ Giangiacomo Torri \\ torri@ronzoni.it \\ Eric Lichtfouse \\ eric.lichtfouse@gmail.com \\ George Z. Kyzas \\ kyzas@teiemt.gr \\ Lee D. Wilson \\ lee.wilson@usask.ca \\ Nadia Morin-Crini \\ nadia.crini@univ-fcomte.fr
}

1 Laboratoire Chrono-environnement, UMR 6249, UFR Sciences et Techniques, Université Bourgogne FrancheComté, 16 route de Gray, 25000 Besançon, France

2 Istituto di Chimica e Biochimica G. Ronzoni, 81 via G. Colombo, 20133 Milan, Italy

3 Aix Marseille Univ, CNRS, IRD, INRA, Coll France, CEREGE, Aix-en-Provence, France

4 Hephaestus Advanced Laboratory, Eastern Macedonia and Thrace Institute of Technology, 65404 Kavala, Greece

5 Department of Chemistry, University of Saskatchewan, 110 Science Place, Saskatoon, SK S7N 5C9, Canada 
trace quantities in their industrial discharge waters. More than 700,000 tons of synthetic dyes are produced worldwide every year, e.g., in India, it is close to 80,000 tons, and $5-10 \%$ of them are discharged in wastewater (Sinha et al. 2016; Karimifard and Moghaddam 2018; Katheresan et al. 2018; Piaskowski et al. 2018). The textile industry (54\%) discharges the largest amount of dye wastewater, contributing to more than half of the existing dye effluents observed in the environment worldwide (Katheresan et al. 2018). The presence of very small amounts of dyes is highly visible and the public perception of water quality is greatly influenced by color. This generates an increasing number of complaints and concern. Contamination of environmental by dyes also poses a serious ecological problem, which is enhanced by the fact that most dyes are difficult to degrade using standard biological treatments. In addition, over the past two decades, there have been concerns about the potential toxicity of dyes and of their precursors, which poses a serious risk to aquatic living organisms (Liu and Liptak 2000; Khalaf 2016; Katheresan et al. 2018).

The removal of pollutants including dyes and pigments from wastewaters is a matter of great interest in the field of water pollution (Forgacs et al. 2004; Pokhrel and Viraraghavan 2004; Aksu 2005; Anjaneyulu et al. 2005; Chuah et al. 2005; Bratby 2006; Crini 2006, 2015; Cox et al. 2007; Hai et al. 2007; Mohan and Pittman, 2007; Wojnárovits and Takács 2008; Gupta and Suhas 2009; Barakat 2011; Sharma and Sanghi 2012; Sharma 2015; Khalaf 2016; Rathoure and Dhatwalia 2016; Morin-Crini and Crini 2017; Alaba et al. 2018; Crini and Lichtfouse 2018). Among the numerous techniques of pollutant removal, adsorption using solid materials - named adsorbents or biosorbents depending on their origin-is a simple, useful and effective process (Crini 2005, 2006). The adsorbent may be of mineral, organic or biological (biosorbent in this case) origin. Activated carbon is the preferred adsorbent at industrial scale. However, its widespread use is restricted due to high cost. In the past three decades, numerous approaches have been studied for the development of cheaper, ecofriendly and more effective biosorbents capable to eliminate pollutants present in synthetic solutions contaminated with a single type of pollutant (Onsoyen and Skaugrud 1990; Peters 1995; Allen 1996; Goosen 1997; Hirano 1997; Ramakrishna and Viraraghavan 1997; Cooney 1999; Blackburn 2004; Gavrilescu 2004; Varma et al. 2004; Crini 2005, 2006; Bhatnagar and Minocha 2006; Oliveira and Franca 2008; Qu 2008; Gadd 2009; Wang and Chen 2009; Elwakeel 2010; Park et al. 2010; Ali 2012; Michalak et al. 2013; Katheresan et al. 2018; Piaskowski et al. 2018). Among the various materials proposed for water and wastewater treatment by biosorption, cross-linked chitosan hydrogels are by far the most widely studied materials, owing not only to their efficiency at eliminating a broad range of pollutants but also to their synthesis that is straightforward and facile (Ravichandran and Rajesh 2013; Liu and Bai 2014; Vandenbossche et al. 2015; Yong et al. 2015; Muya et al. 2016; Nechita 2017; Pakdel and Peighambardoust 2018; Morin-Crini et al. 2019).

In this review, after a brief description of the use of chitosan in wastewater treatment and the basic principles of chitosan-based hydrogels and biosorption, we have chosen to focus on some of the work published on this topic over the past 5 years. The main objectives are to provide a summary of recent information concerning the use of chitosan-based hydrogels as biosorbents and to discuss the main interactions involved in the biosorption process. Recently reported biosorption capacities are also noted to give some idea of biosorbent effectiveness. This article is an abridged version of the chapter published by Crini et al. (2019) in the series Sustainable Agriculture Reviews.

\section{Chitosan for wastewater treatment}

In general, conventional wastewater treatment consists of a combination of mechanical, physical, chemical, and biological processes and operations to remove insoluble particles and soluble pollutants from effluents to reach the decontamination objectives established by legislation. At the present time, there is no single method capable of adequate treatment, mainly due to the complex nature of industrial wastewaters (Crini and Lichtfouse 2018). Among the various treatment processes currently cited for dye removal, only a few are commonly employed by the industrial sector for technological and mostly economic reasons (Morin-Crini and Crini 2017; Crini and Lichtfouse 2018). In practice, a combination of different physical and chemical processes is often used to achieve the desired water quality in the most economical way. Indeed, the main approach used by industry to treat their wastewater containing dyes involves physicochemical methods with, for instance, oxidation, coagulation, precipitation and flocculation of the pollutants by applying chemical agents, then separation by physical treatment of the sludge formed to leave clarified water, and final posttreatment using filtration/adsorption (Berefield et al. 1982; Henze 2001). The use of physicochemical treatment generally enables the legislation concerning liquid industrial effluent to be respected but this conventional treatment does not completely remove pollution. However, as it has to cope with an increasingly strict framework, the industrial sector continues to look into new treatment methods to decrease the levels of pollution still present in the effluent, the aim being to tend toward zero pollution outflow.

In theory, many methods could be suitable to finish off the work done during the physicochemical treatment. These include filtration on sand or carbons, adsorption on 
activated carbons, ion-exchange on resins, membrane filtration, electrodialysis, membrane bioreactors, biological activated sludge, electrocoagulation, electrochemical oxidation, electrochemical reduction, incineration, advanced oxidation, photolysis, catalytic or noncatalytic oxidation, liquid-liquid extraction or evaporation (Liu and Liptak 2000; Henze 2001; Forgacs et al. 2004; Pokhrel and Viraraghavan 2004; Sharma and Sanghi 2012; Khalaf 2016; Crini et al. 2017). Currently, because of the high costs, disposal problems and technical constraints, many of these methods for treating dyes in pretreated effluent have not been widely applied on a large scale. There is a need to develop new removal strategies and decolorization methods that are effective, acceptable in industrial use, and ecofriendly (Crini and Lichtfouse 2018).

It is now well-accepted that, among the numerous techniques of dye removal proposed as secondary or tertiary (final) step in a treatment plant, liquid-solid adsorptionoriented processing is the procedure of choice and gives the best results as it can be used to remove different types of coloring materials (Ravi Kumar 2000; Crini 2006; Gérente et al. 2007; Li et al. 2008; Kyzas et al. 2013a, b; Sanghi and Verma 2013; Dolatkhah and Wilson 2016, 2018; Udoetok et al. 2016). Most commercial systems currently use activated carbon as adsorbent to remove dyes mainly due to its excellent adsorption ability. This technology is also simple, adaptable to many treatment formats, and a large range of commercial products are available from several manufacturers. Activated carbon is extensively used at industrial scale not only for removing dyes from wastewaters streams but also for adsorbing pollutants from drinking water sources, e.g., rivers, lakes or reservoirs. However, although activated carbon is a material of choice, its widespread use is limited due to the high cost of the material and regeneration, particularly for small- and medium-sized enterprises. Moreover, this conventional process is not competitive when faced with very dilute effluents and waters. To overcome this, numerous approaches have been studied for the development of cheaper and effective new materials such as chitosan-based materials.

In the past two decades, these materials used as biosorbents have received much attention in water and wastewater treatment, mainly for metal chelation and dye removal (Kyzas and Kostoglou 2014; Crini 2015; Kos 2016; Muya et al. 2016; Kanmani et al. 2017; Kyzas et al. 2017; Nechita 2017; de Andrade et al. 2018; Desbrières and Guibal 2018; El Halah et al. 2018; Pakdel and Peighambardoust 2018; Wilson and Tewari 2018). Indeed, chitosan has an extremely high affinity for metals and metalloids and for many classes of dyes, including direct, acid, mordant and reactive. In their comprehensive reviews, Crini (2015), Yong et al. (2015), Kyzas et al. (2017), Wang and Zhuang (2017), Desbrières and Guibal (2018), El Halah et al. (2018) and Pakdel and Peighambardoust (2018) recently indicated that biosorption onto chitosan was a promising alternative to replace conventional adsorbents used for decolorization purposes, metal chelation or recovery, and organic removal. With nutraceuticals and cosmeceuticals, the water and wastewater treatment field seems to be the next market in the development of chitosan (Morin-Crini et al. 2019).

Chitosan represents an alternative as ecofriendly complexing agent because of its low cost, its intrinsic characteristics, e.g., renewable, nontoxic and biodegradable resource, and hydrophilicity, and its chemical properties, e.g., polyelectrolyte at acidic $\mathrm{pH}$, high reactivity, coagulation, flocculation and biosorption properties, resulting from the presence of reactive hydroxyl and mostly amine groups in the macromolecular chains (Roberts 1992; Sandford 1989; Skjåk-Braek et al. 1989; de Alvarenga 2011; Teng 2016). These groups allow chemical modifications yielding different derivatives for specific domains of application (Bhatnagar and Sillanpää 2009; Sudha 2011; Azarova et al. 2016; Arfin 2017; Ahmed and Ikram 2017; Sudha et al. 2017; Wang and Zhuang 2017). In wastewater treatment, its use is also justified by two other important advantages: firstly, its outstanding pollutant-binding capacities and excellent selectivity, and secondly, its versatility (No and Meyers 1995, 2000; Peters 1995; Hirano 1997; Houghton and Quarmby 1999; Blackburn 2004; Crini 2005; Crini and Badot 2008; Honarkar and Barikani 2009). Indeed, chitosan possesses a strong affinity to interact with pollutants present in concentrated or diluted solutions, and even at trace levels.

One of the most important properties of chitosan is its cationic nature. This aminopolysaccharide is the only natural cationic polymer in the nature (Roberts 1992; Kurita 1998, 2006; Ujang et al. 2011; Teng 2016). At low pH, usually less than about 6.3, chitosan's amine groups are protonated conferring polycationic behavior to polymer while at higher $\mathrm{pH}$ (above 6.3), chitosan's amine groups are deprotonated and reactive. The protonation reaction is useful because, after dissolution, chitosan can be conditioned under different physical forms. It can be precipitated into beads, cast into films and membranes, spun into fibers, and also crosslinked to produce gels, fibers or sponges (No and Meyers 2000; Kurita 2006; Pillai et al. 2009; Salehi et al. 2016; Shen et al. 2016; Teng 2016; Nechita 2017). The material can be used in solid form for the removal of pollutants from water and wastewater by filtration or adsorption processes or in liquid state, i.e., dissolved in acidic media, for applications in coagulation, flocculation, and membrane filtration (polymer-assisted ultrafiltration) technologies. Among these treatments, biosorption onto cross-linked chitosan hydrogels is one of the more popular methods for dye removal (Miretzky and Cirelli 2011; Muzzarelli 2011; Lee et al. 2012; Reddy and Lee 2013; Lee et al. 2014; Nasef et al. 2014; Vakili et al. 2014; Boamah et al. 2015; Gupta et al. 2015; Kyzas and Bikiaris 2015; Oladoja 2015; Tan et al. 2015; Tran et al. 
2015; Azarova et al. 2016; Barbusinski et al. 2016; Muya et al. 2016; Yang et al. 2016a; Vandenbossche et al. 2015; Zhang et al. 2016; Ahmad et al. 2017; Kyzas et al. 2017; Sudha et al. 2017; Alaba et al. 2018; Bernardi et al. 2018; Pakdel and Peighambardoust 2018; Salehizadeh et al. 2018).

\section{Chitosan-based hydrogels}

The chitosan-based derivatives can be classified into four main classes of materials (Crini 2005; Crini and Badot 2008): modified polymers, cross-linked chitosans, chitosanbased composites, and membranes. An important class of chitosan derivatives are cross-linked gels/hydrogels (Ahmed 2015; Ullah et al. 2015; Akhtar et al. 2016; Mittal et al. 2016; Shen et al. 2016; Xiao et al. 2016; Yao et al. 2016; Aminabhavi and Dharupaneedi 2017; Caccavo et al. 2018; Van Tran et al. 2018). Gels are physically or chemically cross-linked three-dimensional hydrophilic polymeric networks capable of swelling and absorbing large amounts of water (hydrogels), solvent (organogels) or biological fluids (gels/hydrogels) in their swollen state. They also have the ability to interact with a wide range of ions, molecules, oligomers, and polymers. Hydrogels are also versatile materials as they can self-assemble into a variety of forms including microgels/microspheres, beads, nanoparticles/nanogels, films and membranes, fibers/nanofibers, and sponges/ nanosponges, thereby resulting in the formation of $2 \mathrm{D}$ and 3D networks, e.g., spheres, scaffolds, ribbons, and sheets. Once freeze-dried or supercritically dried, hydrogels can also become cryogels or aerogels, respectively.

The different classifications of hydrogels can be found in the reviews by Ahmed (2015) and Ullah et al. (2015). Hydrogels are mainly divided into two classes depending on the types of cross-linking and the nature of their network, namely physical gels and chemical gels. Physical hydrogels are formed by various reversible links and chemical hydrogels are formed by irreversible covalent links. Physicals hydrogels are reversible due to the presence of noncovalent interactions and conformational changes. The hydrogels interconnected by covalent bonds cannot be redissolved (they are permanent) and are thermally irreversible. Hydrogels are also divided into two categories according to their natural or synthetic origin: biopolymer-based or synthetic (Ullah et al. 2015). Due to their hydrophilicity, biocompatibility, biodegradability, "intelligent" swelling behavior, i.e., as responsive materials, and modifiability, i.e., in their structure, functionality, appearance, and electrical charge, biopolymer-based hydrogels have acquired increasing attention and have found extensive applications ranging from biomaterials to sensors (Ullah et al. 2015). Natural polymers such as cellulose, hemicellulose, starch, gelatin, proteins, hyaluronate, and alginates have been proposed and studied
(Jin et al. 2013; Khan and Lo 2016). Chitosan and chitin also deserved particular attention (Pakdel and Peighambardoust 2018).

As semi-flexible, hydrophilic, versatile and reactive biopolymer, chitosan is able to formulate hydrogels in a variety of physical forms from micro- to nano-scale superstructures. Its hydrophilicity is due to the presence of hydroxyl groups. Chitosan-based hydrogels are held together by either physical interactions such as chain entanglements, van der Waals forces, hydrogen bonds, crystallite associations and/ or ionic interactions, or chemical cross-links, i.e., covalent bonding, or a combination of both (Varma et al. 2004; Crini 2005; Tang et al. 2007; Pereira et al. 2017; Sudha et al. 2017). Cross-linking drastically reduces segment mobility in the polymer and a number of chains are interconnected by the formation of new interchain linkages. If the degree of cross-linking is sufficiently high, the product becomes insoluble, regardless of $\mathrm{pH}$, but swellable in water. Its structure is directly dependent on the degree of cross-linking: the higher the degree, the greater proportion of cross-links, making the material rigid, and this decrease the ability of the material to swell in water and/or to interact with pollutants. Crini (2005, 2015), Akhtar et al. (2016) and Khan and Lo (2016) pointed out that the cross-linking density and hydrophilicity of the polymeric chains mainly control the degree of swelling and their ability to absorb and retain a large amount of water or pollutants. Covalent cross-linking, and therefore the cross-linking density, is influenced by various parameters, but mainly dominated by the concentration of cross-linker. It is favored when chitosan molecular weight and temperature increased. Moreover, since cross-linking requires mainly deacetylated reactive units, a high degree of deacetylation of chitosan is favorable.

Due to their reactivity, chitosan-based hydrogels can be prepared under different chemical and physical forms for target applications. Their networks can be nonionic, ionic, or amphoteric in nature and their structure amorphous, semi-crystalline or crystalline (Crini 2005; Jing et al. 2013; Ahmed 2015). These materials have gained relevance for practical applications in pharmacy, e.g., drug carriers, medicine and biomedicine, e.g., wound dressings and tissue engineering scaffolds, cosmetology, hygiene and personal care (superabsorbents), and agriculture, e.g., for pesticide delivery or water retention (Zhang et al. 1993; Dash et al. 2009; Luna-Bárcenas et al. 2011; van Vliergerghe et al. 2011; Ahmadi et al. 2015; Nilsen-Nygaard et al. 2015; Shen et al. 2016; Yao et al. 2016; Zhao 2016; Xiao et al. 2016; Wang et al. 2016; Aminabhavi and Dharupaneedi 2017; Pereira et al. 2017; Pakdel and Peighambardoust 2018; Pellá et al. 2018; Shariatinia and Jalali 2018). They have potential applications in the biotechnology, bioseparation, oil recovery, and biosensor fields. Cross-linked chitosan materials, from gel/ hydrogel types to bead types or particles, have also received 
much attention in wastewater treatment as biosorbents for the removal of metals, dyes, pesticides, phenols, polycyclic aromatic hydrocarbons, polychlorinated biphenyls, pharmaceuticals or fluorides from aqueous solutions (Crini 2015; Yong et al. 2015; Kyzas et al. 2017; Wang and Zhuang 2017; Desbrières and Guibal 2018; El Halah et al. 2018; Pakdel and Peighambardoust 2018; Van Tran et al. 2018). The abundant literature data showed that they exhibited superior performance in the adsorptive removal of a wide range of aqueous pollutants (Pakdel and Peighambardoust 2018; Van Tran et al. 2018). The major advantages and drawbacks of biosorption technology using cross-linked chitosan are listed in Table 1 (Varma et al. 2004; Crini 2005, 2006; Gérente et al. 2007; Crini et al. 2009; Liu and Bai 2014; Rhazi et al. 2012; Sudha et al. 2017).

Various methods have been developed for the chemical cross-linking of chitosan, which commonly result in gel formation (Ahmed 2015; Akhtar et al. 2016; Khan and Lo 2016). These methods are generally divided into three main classes: (1) cross-linking with chemicals, e.g., single emulsion reaction, multiple emulsion, and precipitation/crosslinking; (2) cross-linking and interactions with charged ions, molecules or polymers, e.g., ionotropic gelation, wetphase inversion, emulsification and ionotropic gelation and
(3) miscellaneous methods including thermal cross-linking, solvent evaporation method, spray drying, or freeze drying. Generally, cross-linking with chemicals is an easy method to prepare chitosan-based hydrogels with relatively inexpensive reagents (Crini 2005). Indeed, the main approach in the conversion of chitosan into derivatives capable of interacting with dyes from aqueous solutions involves the direct chemical modification of macromolecules by cross-linking using a chemical agent to form gel/hydrogel systems. This reaction involves creating covalent chemical bonds in all directions in space during a copolymerization reaction that generates a three-dimensional network. In this chemical type of reaction, the cross-linking agents are molecules with at least two reactive functional groups that allow the formation of bridges between polymer chains. To date, the most common cross-linkers used with chitosan are dialdehydes such as glutaraldehyde and epoxides such as epichlorohydrin. Glutaraldehyde and epichlorohydrin are the most frequently used cross-linked agent in chitosan chemistry and their reactions are very well documented (Crini 2005; Kurita 2006; Akhtar et al. 2016). Indeed, they are not expensive and their mode of action is well understood. They react with chitosan chains and cross-link in inter and intramolecular fashion through the formation of covalent bonds with the amino and/or

Table 1 Advantages and disadvantages of using chitosan-based hydrogels for dye removal by biosorption-oriented processes

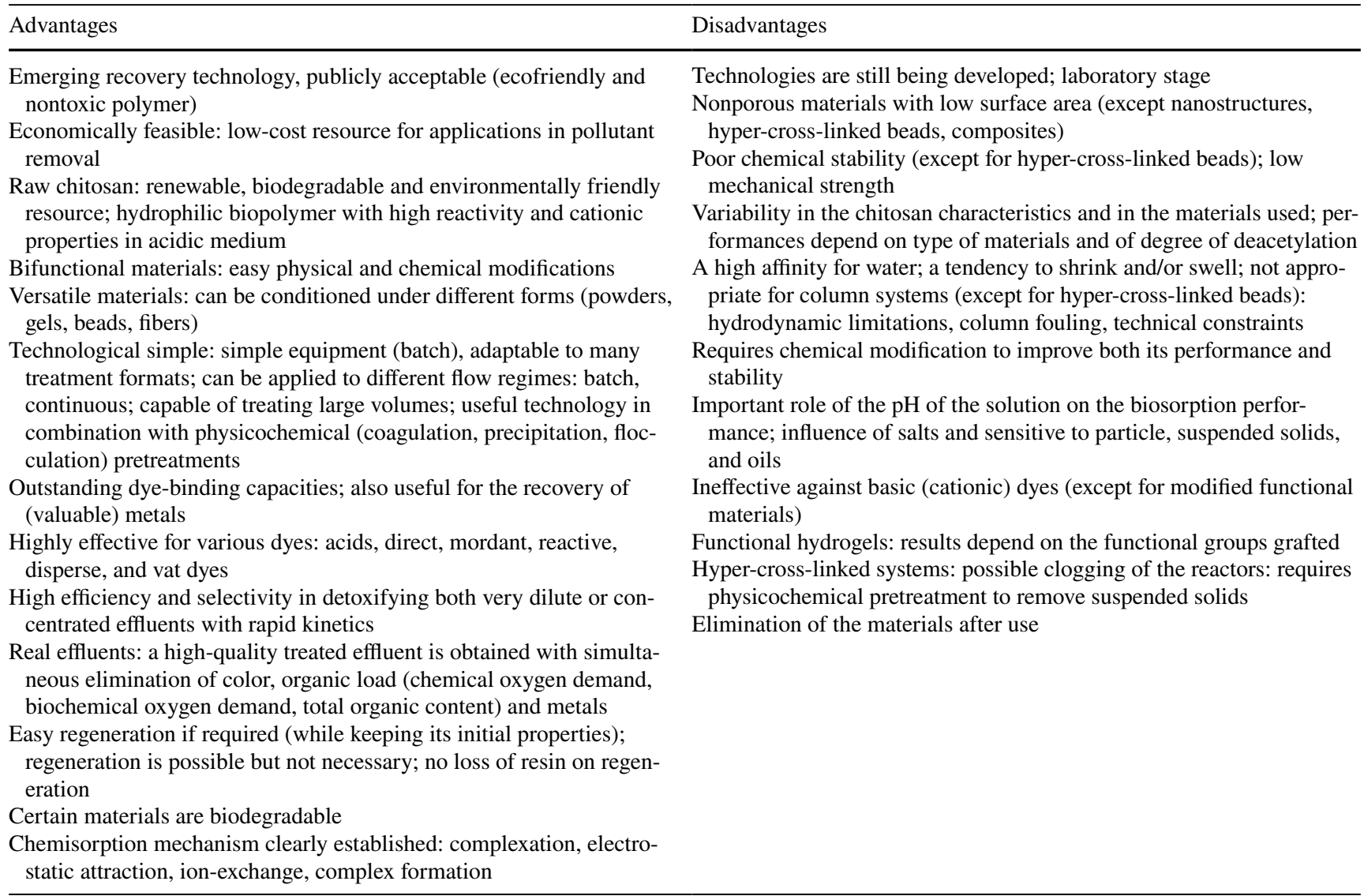



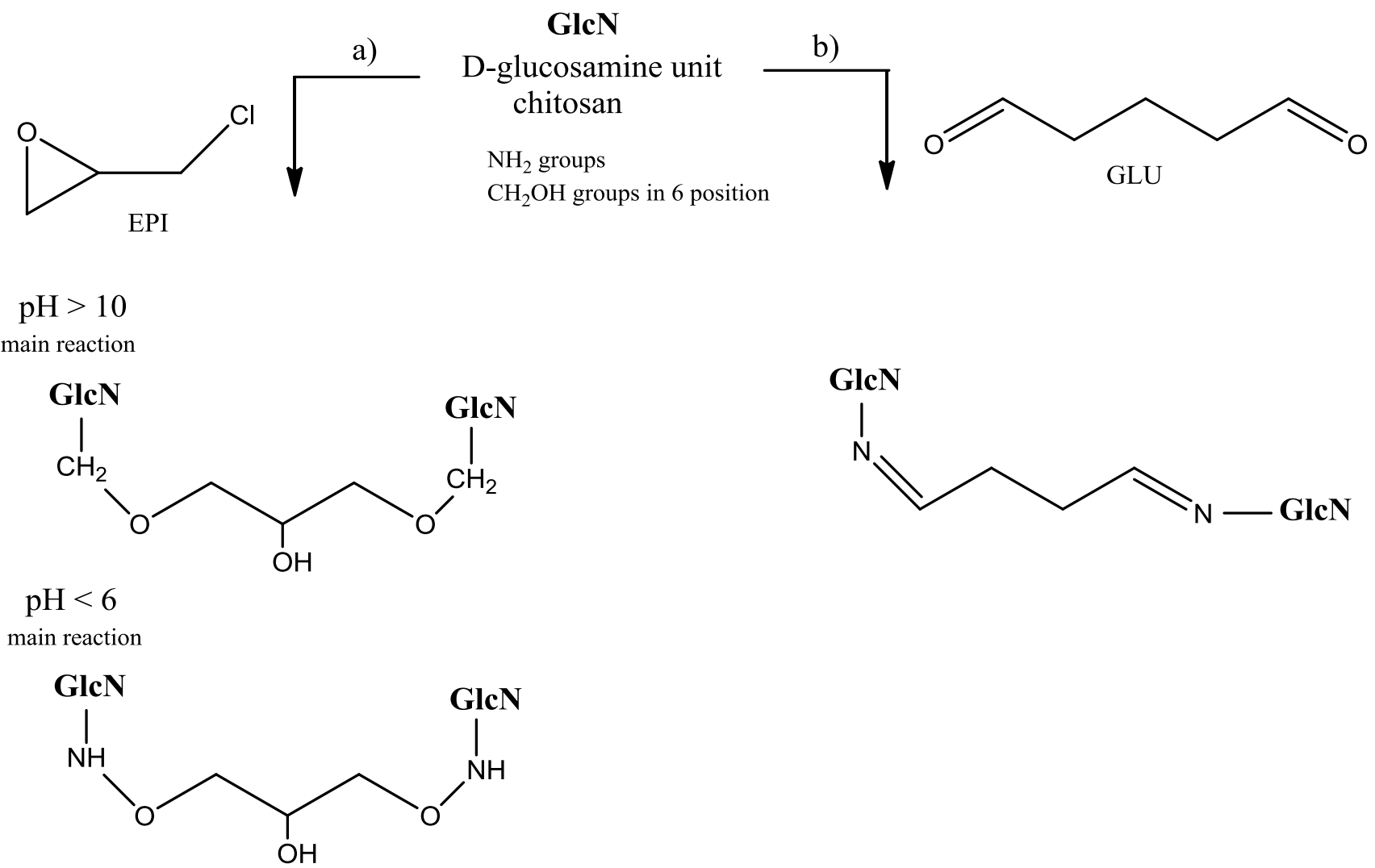

Fig. 1 Synthesis of cross-linked chitosan hydrogels: a epichlorohydrin EPI and b glutaraldehyde GLU

hydroxyl groups of the polymer (Fig. 1). Epichlorohydrin is highly reactive with hydroxyl groups. Another advantage is that it does not eliminate the cationic amine function of chitosan, which is the major adsorption site attracting the pollutant during biosorption process. The main drawback of these two cross-linker agents is that they are considered to be toxic (glutaraldehyde contains cytotoxic chemical species and it is known to be neurotoxic; epichlorohydrin is also considered to hazardous environmental pollutant and potential carcinogen), even if the presence of free unreacted glutaraldehyde and epichlorohydrin is improbable since the materials are purified before use. Other cross-linkers of chitosan are other epoxides such as ethylene glycol diglycidyl ether, carboxylic acids such as citric acid, isocyanates, polyanions such as tripolyphosphate and genipin (Crini 2005; Jin et al. 2013; Shukla et al. 2013; Ahmed 2015; Ullah et al. 2015; Akhtar et al. 2016; Khan and Lo 2016). Recently, silicon oxide polymeric precursors, e.g., tetraethoxysilane, sodium silicates, aminopropyltriethoxysilane, have been proposed. These precursors are interesting because they can form interpenetrated polymers with chitosan after polymerization. The active sites of the biopolymer remain intact while its solubility is diminished and its biosorption capacity is maintained. Nevertheless, most of these approaches involve the obtaining of a hybrid material whose main component is $\mathrm{SiO}_{2}$. Therefore, the overall biosorption capacity of these materials is, in general, lower than that of pure chitosan but these materials have the advantages of high stability, recoverability, and reutilization. In view of industrial developments, these advantages are also of utmost importance.

Generally, a cross-linking step is required to improve mechanical resistance and to reinforce the chemical stability of the chitosan in acidic solutions, modifying hydrophobicity and rendering it more stable at drastic $\mathrm{pH}$, which are important features to define an efficient biosorbent (Crini 2005). However, this reaction can decrease the number of free and available amino groups on the chitosan backbone, and hence the possible ligand density and the polymer reactivity. It also decreases the accessibility to internal sites of the material and leads to a loss in the flexibility of the polymer chains. Moreover, when the cross-linking degree is high, the material is mostly amorphous. So, the chemical step may cause a significant decrease in dye uptake efficiency and biosorption capacities, especially in the case of chemical reactions involving amine groups, since the amino groups of the polymers are much more active than the hydroxyl groups that can be much more easily attacked by cross-linkers. Consequently, it is important to control and characterize the conditions of the cross-linking reaction since they determine and allow the modulation of the cross-linking density, which is 
the main parameter influencing properties of gels (Ahmed 2015; Ullah et al. 2015; Akhtar et al. 2016; de Luna et al. 2017a). Indeed, the conditions of preparation of hydrogels used as biosorbents for dye removal play a crucial role in the determination of their performances and in the better comprehension of the biosorption mechanisms (Crini 2005, 2015). However, this aspect is often neglected in the literature (Ahmed 2015; Crini 2015; Mohamed et al. 2015; Ullah et al. 2015; Akhtar et al. 2016; de Luna et al. 2017a; Pakdel and Peighambardoust 2018; Van Tran et al. 2018).

\section{Removal of dyes from solutions by chitosan-based hydrogels}

There are several types of contacting systems available to obtain experimental data and for industrial applications including batch methods, fixed-bed type processes, pulsed beds, moving mat filters and fluidized beds (Morin-Crini and Crini 2017; Crini and Lichtfouse 2018). The most frequently used system applied in biosorption process for dye removal is the batch-type contact (Fig. 2). This decontamination approach involves mixing a known volume of water with known concentrations of dye to be processed with a given quantity of biosorbent, in previously established conditions of stirring rate, stirring duration, concentration, $\mathrm{pH}$, ionic strength, and temperature. The mixture is stirred for a given contact time and then separated by a physical step involving centrifugation, sedimentation, or filtration. By determining the concentrations in the supernatant and in the initial solution, it is possible to calculate the efficiency of the material, i.e., its performance in terms of dye elimination. In wastewater treatment, the batch method is widely used because this technology is cheap, simple, quick, and easy to set up and, consequently often favored for small- and medium-sized process applications using simple and readily available mixing tank equipment (Morin-Crini and Crini 2017).

In batch systems, the parameters of the solution such as dye concentration, contact time, $\mathrm{pH}$, strength ionic, temperature, etc., can be controlled and/or adjusted. For instance, by varying the quantity of biosorbent, the concentration of the dye(s) or the contact time, it becomes possible to experimentally determine various isotherms (biosorption capacity), kinetics, and the thermochemistry of the process, and also to model them (Al-Duri 1996; Ho and McKay 1998; Wong et al. 2003, 2004; Ho 2006; Hamdaoui and Naffrechoux 2007a, b). Batch studies use the fact that the biosorption phenomenon at the solid/liquid interface leads to a change in the concentration of the solution. Biosorption isotherms are then constructed by measuring the concentration of dye in the medium before and after biosorption at a fixed temperature. By plotting solid-phase concentration against liquid-phase concentration graphically, it is possible to depict an equilibrium adsorption isotherm. This isotherm represents the relationship existing between the amount of pollutant adsorbed and the pollutant concentration remaining in solution. Equilibrium is established when the amount of pollutant being adsorbed onto the material is equal to the amount being desorbed. Among the numerous theories relating to adsorption equilibrium, the Langmuir adsorption isotherm is the best known of all isotherms describing adsorption (Wong et al. 2003, 2004; Hamdaoui and Naffrechoux 2007a, b; Crini et al. 2009; Morin-Crini and Crini 2017). Using an empirical equation introduced by the American chemist and physicist Irving Langmuir in 1916 (Nobel Prize in Chemistry in 1932), it is possible to obtain an interesting parameter widely used in the literature to promote a solid material as adsorbent, i.e., the theoretical monolayer capacity or the maximum adsorption capacity of an adsorbent $\left(\mathrm{q}_{\max }\right.$ in $\left.\mathrm{mg} / \mathrm{g}\right)$. Indeed, the Langmuir isotherm incorporates an easily interpretable constant which corresponds to the highest possible adsorbate uptake in terms of performance.

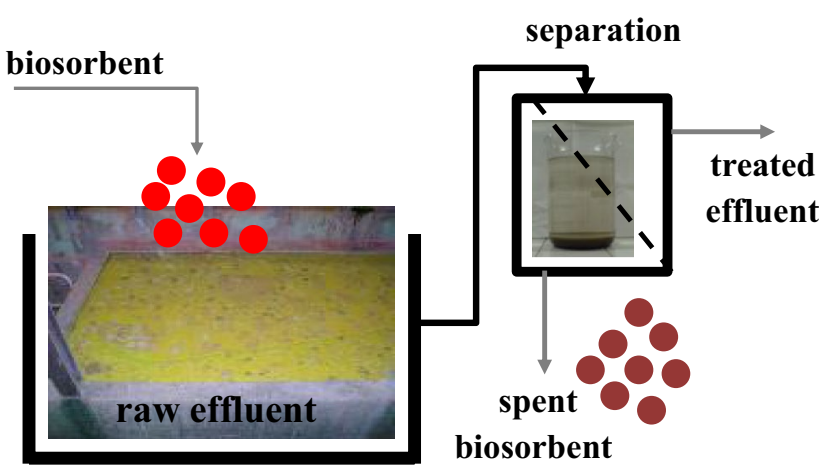

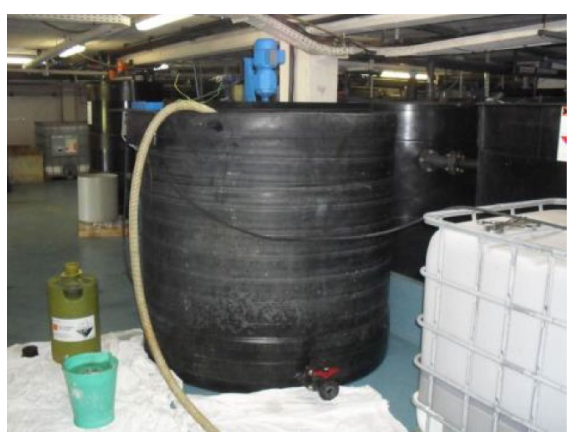

Industrial scale

Fig. 2 Schematic representation of batch process used for dye removal from wastewaters 
It is important to note that, although this theory is the most popular, the model was initially developed for the modeling of the adsorption of gas solutes onto metallic surfaces and is based on the hypothesis of physical adsorption (Langmuir 1916, 1918). The Langmuir equation is represented by Eq. (1) where $\mathrm{x}$ is the amount of dye adsorbed (mg), $\mathrm{m}$ is the amount of biosorbent used $(\mathrm{g}), C_{\mathrm{e}}(\mathrm{mg} / \mathrm{L})$ and $q_{\mathrm{e}}$ $(\mathrm{mg} / \mathrm{g})$ are the liquid-phase concentration and solid-phase concentration of dye at equilibrium, respectively, and $K_{\mathrm{L}}$ $(\mathrm{L} / \mathrm{g})$ and $a_{\mathrm{L}}(\mathrm{L} / \mathrm{mg})$ are the Langmuir isotherm constants. The Langmuir isotherm constants, $K_{\mathrm{L}}$ and $a_{\mathrm{L}}$, are evaluated through linearization of Eq. (1). By plotting $C_{\mathrm{e}} / q_{\mathrm{e}}$ against $C_{\mathrm{e}}$, it is possible to obtain the value of $K_{\mathrm{L}}$ from the intercept which is $1 / K_{\mathrm{L}}$ and the value of $a_{\mathrm{L}}$ from the slope which is $a_{\mathrm{L}} / K_{\mathrm{L}}$ (Eq. 2). Using these constants, it is then possible to obtain $q_{\max }$. Its value, numerically equal to $K_{\mathrm{L}} / a_{\mathrm{L}}$, permits to evaluate the maximum biosorption capacity of a material for the biosorption of a target pollutant. Of course, the uptake of a contaminant by two material biosorbents must be compared not only at the same equilibrium concentration but also in the same experimental conditions (particularly $\mathrm{pH}$ ).

$q_{\mathrm{e}}=\frac{x}{m}=\frac{K_{\mathrm{L}} C_{\mathrm{e}}}{1+a_{\mathrm{L}} C_{\mathrm{e}}}$

$\frac{C_{\mathrm{e}}}{q_{\mathrm{e}}}=\frac{1}{K_{\mathrm{L}}}+\frac{a_{\mathrm{L}}}{K_{\mathrm{L}}} C_{\mathrm{e}}$

\section{Biosorption capacity}

Since the 1990s, a large variety of biosorbents have been proposed and studied for their ability to remove organic contaminants, in particular dye molecules (Gadd 2009). Some of the reported materials include agricultural wastes, industrial by-products, biomass and biopolymers such as polysaccharides. However, biosorbent materials with high adsorption capacities are still under development to reduce the biosorbent dose and minimize disposal problems (Crini and Lichtfouse 2018). Among the numerous biosorbents proposed, much attention has been focused on various chitin-based (Peters 1995; Goosen 1997; Hirano 1997; Li et al. 2008; Bhatnagar and Sillanpää 2009; Sudha 2011; Khor and Wan 2014; Anastopoulos et al. 2017; Sudha et al. 2017) and chitosan-based (Table 2) materials for pollutant removal. Recent results in terms of biosorption capacities using values of the monolayer capacity ( $q_{\max }$ in $\mathrm{mg} / \mathrm{g}$ ) obtained from batch studies were compiled in Table 2 . These reported biosorption capacities must be taken as an example of values that can be achieved under specific conditions since biosorption capacities of the biosorbents presented vary, depending on the characteristics of the material, the experimental conditions, and also the extent of chemical modifications.
The reader is encouraged to refer to the original articles for information on experimental conditions.

Crini (2015), Kyzas et al. (2017), and Wang and Zhuang (2017) demonstrated that biosorption using nonconventional cross-linked chitosan hydrogels is an effective and economic method for water decolorization. These materials had an extremely high affinity for many classes of dyes commonly used in industry with outstanding biosorption capacities, in particular anionic dyes such as acid, reactive and direct dyes (Table 2). For instance, $1 \mathrm{~g}$ of material can adsorb $2498 \mathrm{mg}$ of Reactive Blue 2 present in aqueous solution. In comparison with commercial activated carbons, these nonconventional materials exhibited excellent performance for removal of anionic dyes and the performances were 3-15 times higher at the same pH (Crini 2015; Hadi et al. 2015; Mohamed et al. 2015; Udoetok et al. 2016).

The only class for which chitosan have low affinity is basic (cationic) dyes (Crini 2015). Moreover, it is well known that the uptake is strongly $\mathrm{pH}$-dependent when natural sorbents are used. This is due to the presence of chemical functions on the materials. In general, for anionic dye molecules removal by cross-linked chitosan hydrogels, the highest biosorption effectiveness was achieved at low $\mathrm{pH}$ values, whereas an opposite tendency was observed for cationic dyes removal where an increase in $\mathrm{pH}$ value facilitated enhanced removal of dye. To overcome, these problems, several workers suggested the chemical modification of chitosan in order to decrease the sensitivity of biosorption to environmental conditions, e.g., $\mathrm{pH}$ and ionic strength. The grafting of carboxyl groups, amine functions, and sulfur compounds has been regarded as an interesting method for these purposes (Varma et al. 2004; Crini 2005; Bhatnagar and Sillanpää 2009; Sudha 2011). Other examples can also be found in the reviews by Liu and Bai (2014), Vakili et al. (2014), Azarova et al. (2016), Ahmad et al. (2017), Ahmed and Ikram (2017), Arfin (2017), and Sudha et al. (2017).

The grafting of various functional groups onto the hydrogel network or the chitosan backbone can also improve chitosan's removal performance and selectivity for dye molecules, and also used for controlling diffusion properties. Indeed, these modifications can increase the density of biosorption sites. The presence of new functional groups on the surface of the materials results in an increase in surface polarity and hydrophilicity and this enhances the biosorption of polar sorbates and improves the biosorption selectivity for the target dye. The conditions of preparation of hydrogels and their post-functionalization play a crucial role in the determination of their performances. These performances exhibited by each material relates primarily not only to its chemical properties, e.g., type of functional groups and degree of grafting but also to textural properties (from microspheres to nanoparticles). An overview of the literature data shows that performances strongly depend on the type 
Table 2 Maximum adsorption capacities $q_{\max }$ (in $\mathrm{mg} / \mathrm{g}$ ) for dye removal obtained on different cross-linked chitosan hydrogels using batch studies

\begin{tabular}{|c|c|c|c|}
\hline Cross-linked hydrogel & Dye & $q_{\max }$ & Reference \\
\hline Nanoparticles & Eosin $\mathrm{Y}$ & 3333 & Du et al. (2008) \\
\hline Cyclodextrin-chitosan nanoparticles & Methyl Blue & 2780 & Fan et al. (2012) \\
\hline EPI-chitosan & Reactive Blue 2 & 2498 & Crini (2015) \\
\hline Hydrogel composite & Methylene Blue & 1968 & Melo et al. (2018) \\
\hline Hydrogel composite & Methylene Blue & 1952 & Vaz et al. (2017) \\
\hline EPI-chitosan & Reactive Yellow 86 & 1911 & Crini (2015) \\
\hline Edetate-chitosan (pH 4) & Reactive Yellow 84 & 1883.6 & Jóźwiak et al. (2015) \\
\hline Hydrogel microbeads & Acid Orange 7 & 1670 & Kuroiwa et al. (2017) \\
\hline Urea diammonium tartrate modified chitosan & Congo Red & 1597 & Zahir et al. (2017) \\
\hline Chitosan granules & Reactive Black 5 & 1559 & Jóźwiak et al. (2017a) \\
\hline Diammonium tartrate modified chitosan & Congo Red & 1447 & Zahir et al. (2017) \\
\hline Edetate-chitosan (pH 4) & Reactive Black 5 & 1296.6 & Jóźwiak et al (2015) \\
\hline Powder & Reactive Red & 1250 & Subramani and Thinakaran (2017) \\
\hline Tripolyphosphate-chitosan (pH 4) & Reactive Black 5 & 1125.7 & Filipkowska et al. (2016) \\
\hline Hydrogel composite & Methylene Blue & 1134 & Liu et al. (2018) \\
\hline Quaternary chitosan & Reactive orange & 1060 & Crini (2015) \\
\hline Chitosan nanodispersion & Reactive Red 120 & 910 & Momenzadeh et al. (2011) \\
\hline Polyacrylic acid-chitosan & Methylene Blue & 990 & Li et al. (2017) \\
\hline GLU-chitosan & Reactive Black 5 & 846.9 & Filipkowska et al. (2016) \\
\hline Aerogel & Methylene Blue & 785 & Yang et al. (2016b) \\
\hline Semi-IPN hydrogel & Methylene Blue & 750 & Drăgan et al. (2012) \\
\hline EPI-chitosan & Metanil Yellow & 722 & Crini (2015) \\
\hline Hydroxyapatite-based nanocomposite & Congo Red & 769 & Hou et al. (2012) \\
\hline IPN hydrogel ( $\mathrm{pH} 7)$ & Methyl Violet & 411 & Mandal and Ray (2014) \\
\hline IPN hydrogel (pH 7) & Congo Red & 621 & Mandal and Ray (2014) \\
\hline GLU-chitosan (pH 5) & Reactive Black 5 & 538 & Jóźwiak et al. (2013) \\
\hline GLU-chitosan (pH 3) & Reactive Black 5 & 514 & Jóźwiak et al. (2013) \\
\hline Semi-IPN hydrogel & Acid Red 18 & 342.5 & Zhao et al. (2012) \\
\hline Graphene oxide/chitosan sponge & Methylene Blue & 275 & Qi et al. (2018) \\
\hline GLU-chitosan (pH 9) & Reactive Black 5 & 254 & Jóźwiak et al (2013) \\
\hline Powder & Direct Yellow & 250 & Subramani and Thinakaran (2017) \\
\hline Cyanoguanidine-chitosan & Food Yellow 4 & 210 & Gonçalves et al. (2015) \\
\hline Chitosan-Fe & Acid Red 73 & 206 & Zhou et al. (2017a) \\
\hline Semi-IPN hydrogel & Methyl Orange & 185.2 & Zhao et al. (2012) \\
\hline Cyanoguanidine-chitosan & Food Blue 2 & 180 & Gonçalves et al. (2015) \\
\hline GLU-chitosan (pH 9) & Basic Green 4 & 137 & Jóźwiak et al. (2013) \\
\hline Powder & Malachite Green & 166 & Subramani and Thinakaran (2017) \\
\hline Hyper-cross-linked hydrogel & Indigo Carmine & 118 & de Luna et al. (2017b) \\
\hline Hyper-cross-linked hydrogel & Rhodamine $6 \mathrm{G}$ & 78 & de Luna et al. (2017b) \\
\hline Hyper-cross-linked hydrogel & Sunset Yellow & 72 & de Luna et al. (2017b) \\
\hline $\mathrm{N}$-maleyl chitosan cross-linker & Methylene Blue & 66.89 & Nakhjiri et al. (2018) \\
\hline $\mathrm{N}$-maleyl chitosan cross-linker & Crystal Violet & 64.56 & Nakhjiri et al. (2018) \\
\hline GLU-chitosan (pH 5) & Basic Green 4 & 56 & Jóźwiak et al (2013) \\
\hline Oxide-based nanoparticles & Acid Black 26 & 52.6 & Salehi et al. (2010) \\
\hline Acrylamide-chitosan & Astrazone Blue & 47 & Aly (2017) \\
\hline Terephthaloyl thiourea chitosan & Congo Red & 44 & El-Harby et al. (2017) \\
\hline GLU-chitosan (pH 3) & Basic Green 4 & 19 & Jóźwiak et al. (2013) \\
\hline Semi-IPN hydrogel & Rhodamine B & 17.5 & Al-Mubaddel et al. (2017) \\
\hline Magnetic hydrogel & Methyl Orange & 6.936 & Wang et al. (2018) \\
\hline
\end{tabular}

$E P I$ epichlorohydrin, GLU glutaraldehyde, IPN interpenetrating network 
of material used (Crini 2015; Yong et al. 2015; Kyzas et al. 2017; Wang and Zhuang 2017; Desbrières and Guibal 2018). Indeed, each material has its specific application as well as inherent advantages and disadvantages in dye removal. These problems can explain why it is difficult to develop chitosan-based materials at an industrial scale.

\section{A recent review of the literature on dye removal by chitosan-based hydrogels}

Chitosan-based hydrogels are competitive against conventional sorbents or other biosorbents as recently reported by Li et al. (2017). The authors proposed a versatile low-cost material prepared by simple thermal cross-linking chitosan in the presence of polyacrylic acid. This material $(1 \mathrm{~g})$ was able to remove $990.1 \mathrm{mg}$ of Methylene Blue dye which was higher than most of conventional materials, in parallel agreement with a report by Guo and Wilson (2012). The biosorption properties were reproducible for a wide range of experimental conditions. The interaction between the dye molecules and material was driven mainly by electrostatic attractions. It also presented high selectivity and permitted to separate dye mixtures. The materials were stable and can be recycled for 10 times with negligible reduction of efficiency. The biosorption results were reproducible. In view of industrial development, these features are also of utmost importance. The regeneration of saturated commercial carbon by thermal or chemical procedure is known to be expensive and results in loss of the material. The authors concluded that chitosan complexation was a procedure of choice for dye removal in terms of cost, efficiency, and reusability.

Zahir et al. (2017), El-Sayed et al. (2017), and Lin et al. (2017) also reported that cross-linked chitosan hydrogels were very efficient for the removal of dyes at different concentrations and competitive against commercial systems. The materials exhibited high biosorption capacities toward various dyes present in monocontaminated solutions and possessed a high rate of biosorption, high efficiency and selectivity in detoxifying either very dilute or concentrated solutions. Indeed, chitosan hydrogels are more selective than traditional materials and can reduce dye concentrations to ppb levels. Zahir et al. (2017), El-Sayed et al. (2017), and Lin et al. (2017) concluded that the use of cross-linked chitosan hydrogels as biosorbents was a promising tool for the purification of dye-containing textile wastewaters.

However, the choice of the cross-linking agent has a significant influence on the biosorption properties because the chemical structure of the synthesized beads depends on the nature of the cross-linking agent and the degree of crosslinking. Despite the large number of papers dedicated to the removal of dyes by hydrogels, most of them focus on the evaluation of biosorption performance and only a few of them aim at gaining a better understanding of the role of the cross-linking agent. Copello et al. (2014) proposed chitosan hydrogel beads modified by three different crosslinking treatments, glutaraldehyde and epichlorohydrin and tetraethoxysilane. The authors studied and characterized the behavior of hydrogel cross-linked using a tetraethoxysilane /chitosan ratio of $1 \mathrm{mmol} / \mathrm{g}$. At this ratio, chitosan was in excess compared to tetraethoxysilane, which contrasted with the developments described in the literature where the alkoxysilane was the main component of the composite. The three different hydrogels were used as biosorbent for the removal of an anionic dye, namely Remazol Black. The tetraethoxysilane cross-linking leads to a safer and environmentally friendly hydrogel stable in acidic media and with desirable biosorption characteristics. Their results showed that none of the treatments affected the expected biosorption tendency in regard to media $\mathrm{pH}$. The uptake rate of Remazol Black showed that the three types of beads followed a similar kinetic behavior. The pseudo-first-order model fitted the best for almost all cases, followed by pseudo-secondorder model. The model which showed to have a good fitting for all systems was the Sips model. The performances were strongly pH-dependent. The tetraethoxysilane cross-linked beads demonstrated the higher maximum biosorption capacity, followed by epichlorohydrin and glutaraldehyde crosslinked beads.

Crini (2015) reported that glutaraldehyde interaction with chitosan required the consumption of two glucosamine units to form the corresponding Schiff bases, which leads to a loss of biosorption sites. Moreover, polymerization of glutaraldehyde also occurred forming a greater cross-linking chain which diminished biosorption capacity in terms of dye-mass/biosorbent-mass ratio. Filipkowska et al. (2016) and Udoetok et al. (2016) reported similar conclusions. The experimental data published demonstrated that, compared with glutaraldehyde, the use of a tripolyphosphate-based cross-linking agent increased color removal. The comparison of the maximum biosorption capacity at the same experimental conditions for Reactive Red 5 dye by glutaraldehyde-chitosan and tripolyphosphate-chitosan showed $846.9 \mathrm{mg} / \mathrm{g}$ for glutaraldehyde and $1125.7 \mathrm{mg} / \mathrm{g}$ for pentasodium tripolyphosphate. However, the mechanisms need to be explored.

de Luna et al. (2017a, b) recently developed new composite chitosan-based hydrogels containing hyper-cross-linked polymer particles to be used as broad-spectrum biosorbents. The hydrogels were obtained by phase inversion method in order to efficiently combine the dye biosorption ability of chitosan and the capacity of the porous particles of trapping pollutant molecules. The particles exhibited improved mechanical properties with possible use in batch or column procedures (de Luna et al. 2017a). Batch biosorption experiments revealed a synergistic effect between chitosan and hydrogels, and the samples are able to remove both 
anionic and cationic dyes such as Indigo Carmine $\left(q_{\max }=\right.$ $118 \mathrm{mg} / \mathrm{g})$, Rhodamine 6G $\left(q_{\max }=78 \mathrm{mg} / \mathrm{g}\right)$ and Sunset Yellow $\left(q_{\max }=72 \mathrm{mg} / \mathrm{g}\right.$ ) from water (de Luna et al. 2017b). The maximum dye uptakes were higher than those of comparable biosorbents. However, dependencies in relation to the chemical structure of the dye molecules were not identified. The mechanical properties of hydrogels were enhanced respect to pure chitosan, and the samples can be regenerated and reused keeping their adsorption ability unaltered over successive cycles of biosorption, desorption, and washing. The authors, focusing on the structure-property relationships of chitosan hydrogels, also showed that the conditions of preparations played a crucial role in their performances. The concentration of the starting solution determined the density and strength of intermolecular interactions, and that the gelation kinetics dictated the hydrogel structure at the microscale. Consequently, even subtle changes in the preparation protocol can cause significant differences in the performances of chitosan hydrogels in terms of mechanical properties and dye biosorption capacity. The observed trends can be interpreted looking at the chitosan network structure, which can be inferred by rheological measurements.

In a series of works, Jóźwiak et al. (2013, 2015, 2017a, b) also focused on the structure-property relationships of chitosan hydrogels. Their works compared properties of hydrogel chitosan biosorbents cross-linked with nine agents (Jóźwiak et al. 2017b), including five ionic ones (sodium citrate, sodium tripolyphosphate, sodium edetate, sulfosuccinic acid, and oxalic acid) and four covalent ones (glutaraldehyde, epichlorohydrin, trimethylpropane triglycidyl ether, and ethylene glycol diglycidyl ether). The effect of cross-linking process conditions $(\mathrm{pH}$, temperature) and dose of the cross-linking agent on material stability during biosorption and on the effectiveness of Reactive Black 5 dye biosorption were examined. The influence of chemical nature of chitosan, e.g., degree of deacetylation, was also studied (Jóźwiak et al. 2017a). The optimal parameters of cross-linking ensuring biosorbent stability in acidic solutions and high biosorption capability were established for each cross-linking agent tested. The susceptibility of crosslinked biosorbents to mechanical damages was analyzed as well. The process of ionic cross-linking was the most effective at the $\mathrm{pH}$ value below which hydrogel chitosan biosorbent began to dissolve ( $\mathrm{pH} 4)$. The cross-linking temperature ranging from 25 to $60{ }^{\circ} \mathrm{C}$ had no effect upon biosorbent stability. The higher temperature during ionic cross-linking, however, slightly decreased Reactive Black 5 biosorption effectiveness. The ionic cross-linking significantly decreased the susceptibility of hydrogels to mechanical damages. In the case of covalent cross-linking of chitosan hydrogel beads, the effect of process conditions, e.g., $\mathrm{pH}$ and temperature, on the properties of the cross-linked biosorbent depended on the type of cross-linking agent. The biosorbents cross-linked with covalent agents were usually harder but also more fragile, and therefore more susceptible to mechanical damages. The authors showed that increasing the degree of deacetylation, ranging from 75 to $90 \%$, involved an increase in the relative proportion of amine groups, which were able to be protonated, favoring dye biosorption. The higher degree of deacetylation chitosan provided a better biosorption. The highest biosorption capacity $\left(q_{\max }=1559.7 \mathrm{mg} / \mathrm{g}\right)$ was obtained for the hydrogel in the form of granules (degree of deacetylation $=90 \%$ ). Due to a loose structure and an easy access to biosorption centers, chitosan hydrogel granules may ensure up to $224 \%$ higher biosorption capacity (for degree of deacetylation $=75 \%, q_{\max }=1307.5 \mathrm{mg} / \mathrm{g}$ ) than chitosan in the form of flakes (for degree of deacetylation $=$ $75 \%, q_{\max }=403.4 \mathrm{mg} / \mathrm{g}$ ). The results were also found to be strongly dependent on the $\mathrm{pH}$ of the solution. The authors concluded that biosorption onto hydrogels was a promising alternative to replace conventional materials used for decolorization purposes. These materials were efficient in dye removal with the additional advantage of being cheap and nontoxic. However, their performances were strongly depended on their structure. In particular, the extent of cross-linking was accompanied by a decrease in dye uptake. Moreover, which cross-linking agent is better? There is no direct answer to this question.

El-Harby et al. (2017) investigated the biosorption capacity of three antimicrobial terephthaloyl thiourea crosslinked chitosan hydrogels for Congo Red dye removal. The hydrogels were prepared by reacting chitosan with various amounts of terephthaloyl diisothiocyanate cross-linker in order to study the structure-property relationships of chitosan hydrogels. The results showed that the cross-linking ratio slightly affected the equilibrium biosorption capacity and the performance decreased with an increase in crosslinking density under the range studied. An optimum terephthaloyl thiourea/amine ratio was found for dye biosorption. This decrease in biosorption was interpreted in terms of the decrease in hydrophilicity and accessibility of complexing groups. The cross-linking reaction also decreased the availability of amine groups for the complexation of dyes. The biosorption isotherms and kinetics showed that the experimental data were better fitted by the Langmuir equation and the pseudo-second-order equation, respectively. Isotherms were characterized by a steep increase in the biosorption capacity, indicating a great affinity of the hydrogel for the dye, followed by a plateau representing the maximum capacity at saturation of the monolayer $\left(q_{\max }=44.2 \mathrm{mg} / \mathrm{g}\right)$. The biosorption phenomena were most likely to be controlled by chemisorption process. It was spontaneous in nature, indicated by the negative value for the Gibbs energy change $\Delta G$, more favorable at lower concentrations of dye molecules compared with higher concentrations, and was most likely to be controlled by chemisorption. The positive values of 
enthalpy change $\Delta H$ and entropy change $\Delta S$ suggested the endothermic nature of biosorption and increased randomness at the solid/solution interface during the biosorption of dye on chitosan derivatives. The authors concluded that cross-linked chitosan hydrogels may be promising biosorbents in wastewater treatment.

Recently, some novel procedures such as irradiationbased techniques, e.g., ionizing radiation, gamma rays, and electron beam, have been reported for cross-linking polysaccharides. The preparation of gels by radiation treatment carries some advantages over the conventional methods. The reaction can be initiated at ambient temperature and, in certain cases, it does not require the presence of crosslinking agents. The method is also relatively simple and the process control is easy. The degree of cross-linking, which strongly determines the extent of properties in gels, can be easily controlled by varying the irradiation dose. In the synthesis of gels by chemical methods, cross-linking density is controlled by the concentration of the cross-linker, reaction time, temperature and other factors. While for the radiation method it is determined by the absorbed dose, which means by the irradiation time. Moreover, cross-linking by the chemical methods is generally performed mainly in the liquid state. Since the ionizing radiation is highly penetrating, it is possible to initiate chemical reactions in liquid or in solid state. Piątkowski et al. (2017) proposed a novel, wastefree method for obtaining multifunctional chitosan hydrogels under microwave irradiation without the presence of a crosslinking agent. Their chemical and morphological structure, swelling properties, and biosorption capability of a model dye were described. Bifunctional materials containing both negative and positive surface charges were fully biodegradable, and capable to absorb high amounts of water, as well as to remove various water contaminants.

Wach's group has applied electron beam irradiation to prepare gels from chitosan. They synthesized a series of novel gels of carboxymethylated chitosan derivatives by electron beam for biomedical applications and their characteristics are being studied in detail (Mozalewska et al. 2017; Czechowska-Biskup et al. 2016). Solutions of chitosan and carboxymethyl-chitosan were subjected to irradiation by electron beam in the presence of poly(ethylene glycol) diacrylate in order to produce carboxymethyl-chitosan- and chitosan-based hydrogels. Poly(ethylene glycol) diacrylate monomer itself undergoes simultaneous polymerization and cross-linking either in neutral water or in acidic medium. Acidic solutions of chitosan of $0.5,1$ and $2 \%$ can be effectively cross-linked with poly(ethylene glycol) diacrylate to form a gel. Although carboxymethyl-chitosan undergoes radiation-initiated cross-linking only at high concentration in water (over 10\%), the presence of poly(ethylene glycol) diacrylate in solution facilitated hydrogel formation even at lower concentration of carboxymethyl-chitosan. The formation of chitosan and carboxymethyl-chitosan hydrogels required irradiation doses lower than those needed for sterilization, i.e., $25 \mathrm{kGy}$, in some cases even as low as $200 \mathrm{~Gy}$. Sol-gel analysis revealed relatively high gel fraction of obtained hydrogels, up to $80 \%$, and good swelling ability. Both parameters can be easily controlled by composition of the initial solution and irradiation dose. Possible mechanisms of cross-linking reactions were proposed, involving addition of the polysaccharide macro-radicals to a terminal double bond of poly(ethylene glycol) diacrylate. Even though the polymer chains may be partly degraded during irradiation, the authors concluded that ionizing radiation was a convenient tool to synthetize hydrogels based on chitosan for potential applications not only in the biomedical field but also in water and wastewater treatment.

Practical industrial applications of hydrogels in columnbased biosorption processes are limited due to hydrodynamic limitations (Esquerdo et al. 2014, 2015). Certain hydrogels are also too soft and degrade at fast rates which can pose major handling difficulties during their applications. Various hyper-cross-linked chitosan gels/beads, chitosan scaffolds, sponges, and chitosan-based composites have been designed to overcome these problems. Different techniques such as blending between two or more polymers, copolymerization with (hydrophobic) synthetic monomers, synthesis of interpenetrating network and semi-interpenetrating network have been proposed. These techniques are useful because they improve the mechanical strength, enhance swelling/deswelling response and avoid the loosening of their structure in wet environments. Dragan (2014) reviewed the main synthesis strategies of fully- and semi-interpenetrating network hydrogels and their potential applications.

Hyper-cross-linked hydrogel beads were prepared from monodisperse water-in-oil emulsions using a microchannel emulsification technique for the first time and proposed for Acid Orange 7 removal by Kuroiwa et al. (2017). Monodisperse emulsion droplets can be generated spontaneously via an interfacial tension-driven process without generating severe shear force and heat by a two-step gelation process. They were formed by physical gelation of chitosan-containing water droplets by alkali treatment followed by chemical cross-linking treatment using ethylene glycol diglycidyl ether. To clarify the effect of various process parameters such as chitosan concentration and flow rate of chitosan solution on the emulsification, microchannel emulsification was performed under various conditions. The mean diameter and diameter distribution were affected by the viscosity and flow rate of the chitosan solution pressed into microchannels. The biosorption results showed that chitosan gel microbeads exhibited high biosorption capacities toward Acid Orange $7\left(q_{\max }=1670 \mathrm{mg} / \mathrm{g}\right)$. Electrostatic attractions between the positively charged polymer chains $\left(-\mathrm{NH}_{3}{ }^{+}\right.$groups $)$and the negatively charged anionic dye 
molecules $\left(-\mathrm{SO}_{3}{ }^{-}\right.$groups) were the most prevalent mechanism with the $\mathrm{pH}$ as the main factor affecting performances. Although these properties were $\mathrm{pH}$ responsive, the microbeads can be applied under acidic and neutral $\mathrm{pH}$ conditions. The high value of $q_{\max }$ suggested that the molar ratio of $-\mathrm{NH}_{3}{ }^{+} /-\mathrm{SO}_{3}{ }^{-}$was $1.0 / 0.82$ at maximum biosorption, i.e., $82 \%$ of $-\mathrm{NH}_{3}{ }^{+}$groups in chitosan hydrogel would be bound to $-\mathrm{SO}_{3}{ }^{-}$. This result indicated that the biosorption was achieved by electrostatic interactions. The microbeads were also stable for more than 120 days and could be reused in repetitive adsorption-desorption cycles (at least 10 times) without decrease in performance. The authors concluded that these new hydrogels would be interesting in wastewater treatment for the removal of anionic organic dyes due to their intrinsic properties (small diameter $<20 \mu \mathrm{m}$, high size uniformity with coefficient of variation $<10 \%$ ), outstanding biosorption performance, high stability under various conditions, and reusability. The preparation of chitosan-containing emulsions and chitosan gel microbeads using the microchannel emulsification technique represents an innovative and easy method of preparation.

Esquerdo et al. (2014) prepared a chitosan scaffold with a mega-porous structure as an alternative biosorbent to remove food dyes from solutions. The new material was characterized by infrared spectroscopy, scanning electron microscopy and other structural tools. It presented pore sizes from 50 to $200 \mu \mathrm{m}$, porosity of $92.2 \pm 1.2 \%$ and specific surface area of $1135 \pm 2 \mathrm{~m}^{2} / \mathrm{g}$. Its potential to remove five food dyes from solutions was investigated by equilibrium isotherms and thermodynamic studies. The chitosan megaporous scaffold showed both good structural characteristics and high biosorption capacities $(788-3316 \mathrm{mg} / \mathrm{g}$ ) at $298 \mathrm{~K}$. The two-step Langmuir model was suitable to represent the equilibrium data. The process was spontaneous, favorable, exothermic and an enthalpy-controlled process. Results were explained by the presence of electrostatic interactions that occurred the between chitosan scaffold and dye species. This was demonstrated from infrared spectroscopy, and scanning electron microscopy with energy dispersive $\mathrm{X}$-ray mappings.

New interpenetrating network hydrogels were prepared by Mandal and Ray (2014) from chitosan and cross-linked copolymers of acrylic acid, sodium acrylate and hydroxyethyl methacrylate. Acrylic acid, sodium acrylate, hydroxyethyl methacrylate and N'N'-methylenebisacrylamide monomers were free radically copolymerized and then cross-linked in aqueous solutions of chitosan. Several interpenetrating network hydrogels were prepared by varying the concentration of initiator and weight (\%) of chitosan. The biosorption of cationic Methyl Violet and anionic Congo Red dyes by these hydrogels were studied. The materials showed high abatement expressed in \% (98-73\% for Congo Red and 94-66\% for Methyl Violet) over the feed concentration of $10-140 \mathrm{mg} / \mathrm{L}$ of dye in water. The materials were $\mathrm{pH}$ responsive and the performances depended on the type of hydrogel. Hydrogels prepared with $1 \mathrm{wt} . \%$ initiator, $1 \mathrm{wt} . \%$ cross-linker and $12 \mathrm{wt} . \%$ chitosan showed the best swelling characteristics and performances. The good reusability of the materials was another cited advantage (Mandal and Ray 2014).

Semi-interpenetrating network technology is a feasible route to produce new hydrogels as recently reported by Al-Mubaddel et al. (2017). It is a combination of two or more polymers in which one forms a network and the other remains in a linear form. The linear polymer remains physically bonded to the network via various interactions such as electrostatic forces, hydrophobic interactions, and van der Waals forces. Using this technology, the authors prepared chitosan/polyacrylonitrile semi-interpenetrating network hydrogel via glutaraldehyde vapors for Rhodamine $B$ removal from aqueous solutions. The main advantages of these hydrogels as biosorbents include ease in loading, chelation complex formation, semi-continuous operation, wettability and high swelling, and reusability. Wettability and swelling facilitate the biosorption of target molecules since swelling provides more specific surface area and expose more functional groups for biosorption.

Cross-linked hydrogels with glutaraldehyde and hydrogels with activated carbon were developed, characterized and applied for the biosorption of Food Blue 2 and Food Red 17 from aqueous binary system by Gonçalves et al. (2017). Their results revealed that the insertion of activated carbon on the chitosan hydrogel structure provided an improvement in the biosorption performance. The materials can be easily regenerated by alkaline solutions and were reusable for more than 5 cycles. The biosorption capacities remained unchanged after regeneration, showing that both the chemical stability of the composites and reproducibility of the biosorption process.

The interaction between a new hydrogel composite (chitosan-poly(acrylic acid)/rice husk ash hydrogel) and Methylene Blue was investigated by Vaz et al. (2017). Their studies clearly indicated that the hydrogel had a natural selectivity for dye molecules and was very useful for the treatment of wastewater. Biosorption capacities ranged from 1450 to $1950 \mathrm{mg} / \mathrm{g}$ with increasing the initial Methylene Blue concentration from 1500 to $2500 \mathrm{mg} / \mathrm{L}$ at $\mathrm{pH}>5$. The removal efficiency was higher than $90 \%$ for all samples. The dye biosorption onto the composite material was spontaneous in nature and the kinetic measurements showed that the process was rapid (the equilibrium time was found to be $60 \mathrm{~min}$ in all the experiments). The biosorption system obeyed the pseudo-second-order kinetic model for the entire biosorption period studied. Using kinetic studies, the authors also showed that the mechanism of action was chemisorption rather than physisorption. After saturation, the hydrogels are easily regenerated in acidic solution and after five cycles of 
biosorption/desorption, they maintained their dye removal efficiency ( $>91 \%)$.

Zhou et al. (2017b) proposed new nano- $\mathrm{TiO}_{2} /$ chitosan/ poly(N-isopropylacrylamide) composite hydrogels by using a two-step polymerization synthetic method. The hydrogels exhibited both high biosorption capacity and efficiency of photocatalytic degradation for Acid Fuchsin dye. The mechanism was clearly established for the interpretation of experimental data. Dye elimination is assumed to occur through chemisorption with the $\mathrm{pH}$ as the main factor affecting the process. Amine sites were the main reactive groups for dyes even though hydroxyl groups may also contribute to the biosorption process. The biosorption performance was observed to be $\mathrm{pH}$-dependent. An accurate mathematical description of biosorption capacity at equilibrium was indispensable for reliable prediction of biosorption parameters and quantitative comparison of adsorption behavior for different materials and/or for varied experimental conditions.

Liu et al. (2018) synthesized a three-dimensional porous beta-cyclodextrin/chitosan functionalized graphene oxide hydrogel by a simple and facile chemical reduction method in the presence of sodium ascorbate which acted as a reducing agent. This new hydrogel was used as biosorbent to remove Methylene Blue from aqueous solutions. The material showed an ultrahigh biosorption capacity $(1134 \mathrm{mg} / \mathrm{g}$ ) for this dye. The unique 3D structure enabled the rapid reuse and recyclability of hydrogel without a complicated filtration system. The biosorption process was well fitted with the pseudo-second-order equation and Freundlich model. The simulation of the intraparticle diffusion model illustrated that both film diffusion and intraparticle diffusion were involved in the process. The characteristics of hydrogels were expressed in thermodynamic parameters, indicating that the biosorption process was spontaneous and endothermic. The authors concluded that this new material could be a cost-effective and promising biosorbent for dye removal.

Graphene oxide-based materials were recently proposed for potential application in water treatment. Although these materials have shown high performance in both concentrated and diluted solutions, their separation from water for reuse remains a challenge. Qi et al. (2018) investigated the self-assembly of graphene oxide sheets in the presence of chitosan into sponges. The results showed that about $93 \%$ of added chitosan could be combined with graphene oxide, regardless of the chitosan concentration. Upon freeze drying, a stable sponge was generated only at a chitosan content of $\geq 9 \%$. The $q_{\max }$ for Methylene Blue was determined to be 275.5 of dye per gram of material. The performances increased with the chitosan content between 9 and $41 \%$. From X-ray diffraction, scanning electron microscopy and transform infrared spectroscopy data, both electrostatic attraction and hydrophobic interactions were responsible for Methylene Blue biosorption by sponges. Another advantage was the use of fixed-bed column and the easy recycling of the materials after biosorption. Indeed, desorption can be carried out in the same column using an alkaline solution. This regeneration step restored the material close to the original condition for effective reuse with undiminished dye uptake and no physical change or damage. Sabzevari et al. (2018) similarly demonstrated the utility of cross-linking chitosan with graphene oxide to yield adsorbent materials with greater adsorption over that of colloidal graphene oxide with Methylene Blue. The facile cross-linking strategy of graphene oxide reveals that such polymer composites display tunable physicochemical properties and functional versatility for a wider fields of application versus graphene oxide, especially for contaminant removal over multiple adsorption-desorption cycles.

Melo et al. (2018) proposed the use of cellulose nanowhiskers to enhance the biosorption capacity of chitosan$g$-poly(acrylic acid) hydrogel. The composites contained up to $20 \mathrm{w} / \mathrm{w}-\%$ cellulose nanowhiskers showed an improved biosorption capacity toward Methylene Blue as compared to the pristine hydrogel. At $5 \mathrm{w} / \mathrm{w}-\%$ cellulose nanowhiskers, the biosorbent presented the highest performance $\left(q_{\max }=\right.$ $1968 \mathrm{mg} / \mathrm{g}$ ). The maximum removal of Methylene Blue ( $>$ $98 \%$ of initial concentration $2 \mathrm{~g} / \mathrm{L}$ ) was achieved at the following conditions: contact time $60 \mathrm{~min}, \mathrm{pH} \mathrm{6}$, ionic strength $0.1 \mathrm{M}$, and room temperature. The biosorption mechanism was explained with the Langmuir type I model suggesting the formation of a Methylene Blue monolayer on the material surface. Using kinetic data, the interaction between the biosorbent and dye molecules was explained by chemisorption. The regeneration step was easy and the materials were regenerated at low cost by a simple immersion with an acidic solution. They were reusable more than 5 cycles without any loss of mechanical or chemical efficacy. This change in the $\mathrm{pH}$ of the solution reversed the biosorption because the electrostatic attraction mechanism was very sensible to $\mathrm{pH}$.

Yang et al. (2016b) developed a novel green biopolymer-based aerogel by freeze drying a hydrogel from crosslinking bifunctional hairy nanocrystalline cellulose and carboxymethylated chitosan through a Schiff base reaction. The authors used a sequential periodate and partial chlorite oxidation of cellulose, followed by a hot water treatment. The nanocelluloses, bearing aldehyde and carboxylic acid groups, facilitated the cross-linking with chitosan through imine bond formation while providing negatively charged functional groups, where chitosan was modified to accommodate carboxylic acid. The material was highly porous (pore size in the range of 35-70 $\mu \mathrm{m}$ ) and negatively charged (the carboxyl group content was $3.2 \mathrm{mmol} / \mathrm{g}$ ). It showed excellent biosorption performance over a wide range of $\mathrm{pH}$. At $\mathrm{pH}=7.5$, the maximum Methylene Blue dye biosorption capacity of the aerogel was $785 \mathrm{mg} / \mathrm{g}$, obtained by fitting the equilibrium data to 
the Langmuir isotherm, yielding the highest biosorption capacity for any reported reusable biosorbents prepared from biopolymers. The performance was also comparable to commercial activated carbon $(980.3 \mathrm{mg} / \mathrm{g}$ ) and an asreceived starch microparticle $(716.3 \mathrm{mg} / \mathrm{g})$, reported by Karoyo et al. (2018). The maximum biosorption is about $86 \%$ of the amount calculated from charge stoichiometry, i.e., in reference to the chitosan carboxylated materials. The mechanism was explained by electrostatic complexation between acidic groups on the anionic aerogel with the cationic dye. At $\mathrm{pH}=3$, the $q_{\max }$ was about $192 \mathrm{mg} / \mathrm{g}$, which was about $25 \%$ of the maximum biosorption at $\mathrm{pH}$ $=7.5$. This decrease was due to the protonation of carboxylic acid groups. Dynamics of biosorption was modeled by numerically solving the unsteady-state diffusionsorption mass balance in a 1D spherical coordinate, which attested to a diffusion-controlled process. The aerogel can be regenerated using acidic solution $(\mathrm{pH}<2)$ in $60 \mathrm{~min}$. Successful biosorption-regeneration cycles proved an excellent reusability (at least six cycles), and the biosorption capacity remained constant over a wide $\mathrm{pH}$ range.

\section{Biosorption mechanisms}

In the context of adsorption technology, the major challenge is to select the most promising types of adsorbent, mainly in terms of high capacity, often expressed by the $q_{\max }$ value. The next real challenge is to clearly identify the mechanism.
For chitosan hydrogels used for the removal of dyes, the mechanisms have been demonstrated (Crini and Badot 2008; Elwakeel 2010; Sudha 2011). Biosorption involves similar binding mechanisms than those used with commercial synthetic organic resins, where dye binding takes place essentially on amine groups, although the contribution of hydroxyl groups is also possible. In general, dye elimination by chitosan involves two different mechanisms, complexation versus ion-exchange, depending on the $\mathrm{pH}$ since this parameter may affect the protonation of the macromolecule chains. Amine groups are susceptible to ionization as a function of $\mathrm{pH}\left(\mathrm{pk}_{\mathrm{a}}\right.$ values in the range 6.3-6.5), that allow chitosan to form a polycation species. Hence, the protonated amine groups can form complexes with anionic species by electrostatic attractions and/or ion-exchange (Guo and Wilson 2012; Olivera et al. 2016; Salehi et al. 2016; Kyzas et al. 2017; Subramani and Thinakaran 2017; Wang and Zhuang 2017; Karimi et al. 2018). Figure 3 illustrates the mechanism of anionic dye adsorption by a cross-linked chitosan hydrogel under acidic conditions. In this case, the main interaction is electrostatic attraction.

It is also possible that these two interactions can occur simultaneously depending on the composition of the material, the dye structure and its properties, and the solution conditions, e.g., $\mathrm{pH}$, ionic strength and temperature. In neutral or alkaline solutions, chitosan is a weakly alkaline material due to the fact that amino groups are deprotonated. These reactive groups can bind dye species by complexation
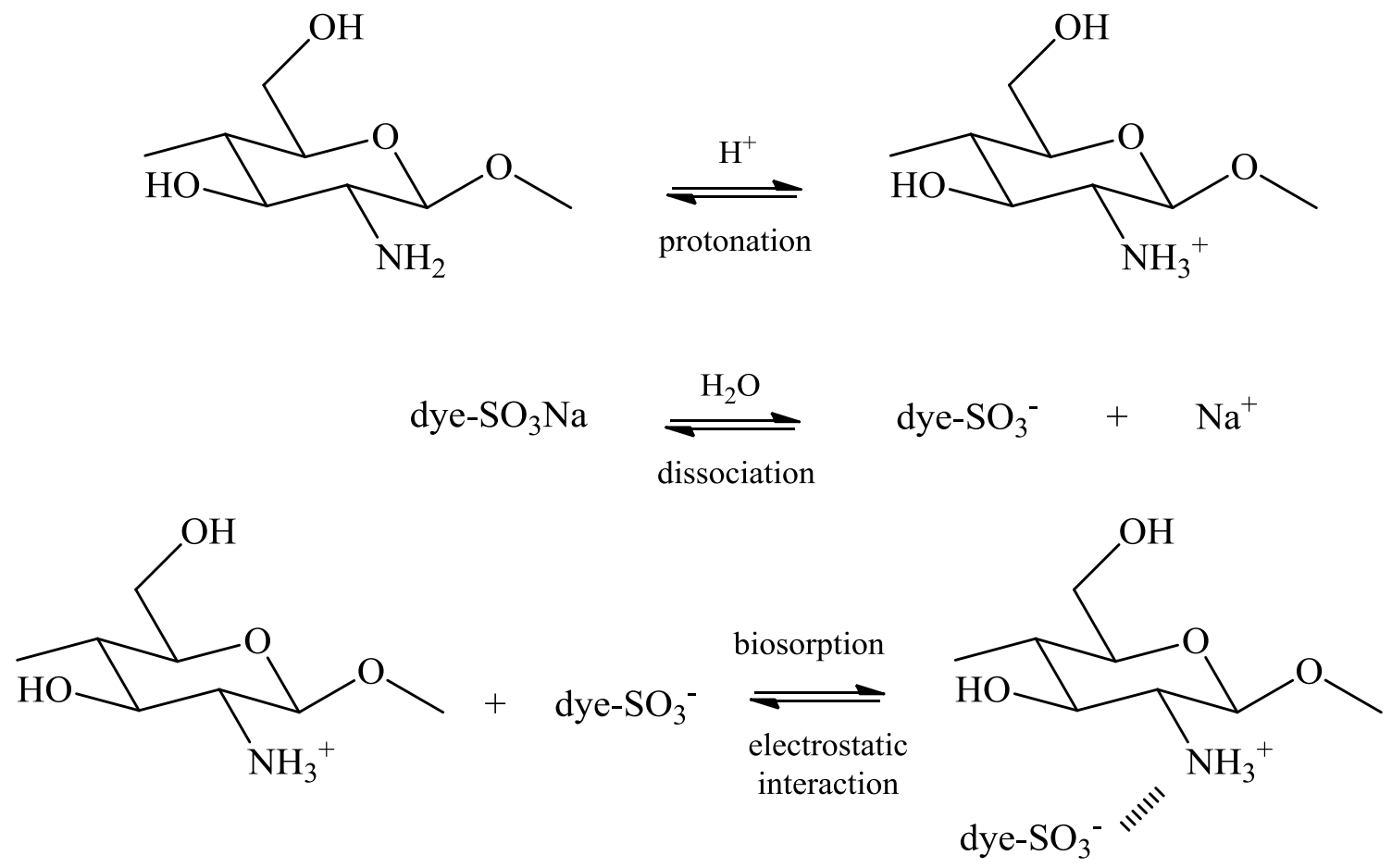

Fig. 3 Mechanism of anionic dye adsorption by a cross-linked chitosan hydrogel under acidic conditions 
including chelation and coordination. Some of other reported interactions cited in other studies also include surface adsorption, physical adsorption and diffusion in the macromolecular network, hydrogen bonding (hydroxyl groups contribute to stabilizing dye binding on amine groups), and acid-base interactions.

\section{Personal comment}

Future research needs to explore some of the following aspects. To date, despite the large number of papers devoted to the biosorption of dyes onto chitosan hydrogels, the outstanding removal capabilities reported reveal unquestionable progress. However, biosorption processes of such materials are often limited by laboratory-based studies (Crini 2015). Indeed, the materials have already been shown to be effective in laboratory experiments, but no pilot-scale demonstration has yet been carried out.

As industrial production of cross-linked chitosan hydrogels has not started, the biosorbents produced at lab-scale suffer from variability in their characteristics and lack of reproducibility, e.g., difficulty to produce materials at the same cross-linking density. Indeed, although various laboratories and a few companies can synthesize these materials to order, it is very difficult to find commercial sources of cross-linked hydrogels with guaranteed reproducible properties. Yet, the performance can vary depending on the conditions and the mode of preparation of hydrogels. However, this aspect is often neglected in the literature (Ahmed 2015; Ullah et al. 2015; Akhtar et al. 2016; de Luna et al. 2017a; Pakdel and Peighambardoust 2018; Van Tran et al. 2018). A more detailed study appears to be necessary to show how the chemical structure of the hydrogels affects the biosorption performance.

Most studies focused on solutions contaminated with a single type of dye using standard conditions. Studies involving treatment of polycontaminated solutions and real effluents are indeed scarce. The experimental conditions should be chosen to simulate real wastewater on the basis of thermodynamics and studies of reaction kinetics. Much work in this area is necessary to demonstrate the possibilities on an industrial scale. Moreover, in spite of the abundance of literature reports, there is yet little information that details comprehensive studies that compare various biosorbents and conventional commercial adsorbents at similar conditions. Comparisons of different materials are however difficult because of inconsistencies in the manner of data presentation. Due to scarcity of consistent cost information, cost comparisons are also difficult to make. This economic aspect is often neglected.

In addition, there is no systematic and comparative study taking into account the physicochemical properties of the different kind of dyes. Recently, some investigators have focused on studying the influence of the chemical structure of dyes on biosorption capacity. These studies would help in optimizing the type and amount of chitosan, i.e., in reference to material dosage and/or the manner in which composite materials are prepared. The development of mechanistic and mathematical models in order to simulate the biosorption process are also important aspects in future studies that should be further developed.

Finally, most studies have focused on the evaluation of biosorption performance, where only a few aim at gaining a greater understanding of the desorption strategy. On this topic, Kyzas et al. (2014) developed a phenomenological model which was capable of describing the data for all the initial dye concentrations. The model was extended to repeated batch biosorption/desorption cycles. Results showed that the decrease in biosorption efficiency during the cycles can be attributed to the requirement for total adsorbate mass conservation during each step, rather than thermodynamic irreversibility of the process. The inherent irreversibility cannot be identified by the biosorption /desorption cycle only, but requires advanced diagnostic tools such as spectroscopic techniques to show any changes in the structure and functional groups of the biosorbent.

\section{Conclusion}

The past two decades have shown an explosion in the development of new hydrogels that contain chitosan for use as biosorbents in dye removal from solution. Their potential use in biosorption-oriented processes is now recognized. However, in spite of numerous results, publications, and patents, cross-linked chitosan hydrogels are not yet produced on an industrial scale and are still not widely used for water treatment. Nevertheless, they will find industrial environmental applications due to their outstanding biosorption capacities and efficiency to treat either concentrated or diluted solutions of contaminants in aqueous media. In Europe, the tightening of regulations concerning effluent implies a better level of treatment of waste to tend toward zero pollution. With most types of conventional water treatment, it is difficult to remove pollutants including dyes present at low or very low levels in heterogeneous and variable effluents. Cross-linked chitosan hydrogels are shown to have efficacy to remove pollution present at trace levels. Further efforts will be necessary to convince industry to use these materials as part of the treatment strategy in their wastewater treatment plants. 


\section{References}

Ahmad M, Kaiser M, Ikram S (2017) Versatile nature of hetero-chitosan based derivatives as biodegradable adsorbent for heavy metal ions. A review. Int J Biol Macromol 105:190-203. https:// doi.org/10.1016/j.ijbiomac.2017.07.008

Ahmadi F, Oveisi Z, Mohammadi Samani S, Amoozgar Z (2015) Chitosan based hydrogels: characteristics and pharmaceuticals applications. Res Pharm Sci 10:1-16

Ahmed EM (2015) Hydrogel: preparation, characterization, and applications: a review. J Adv Res 6:105-121. https://doi.org/10.1016/j. jare.2013.07.006

Ahmed S, Ikram S (eds) (2017) Chitosan-derivatives, composites and applications. Scrivener Publishing LLC, Beverly, p 516

Akhtar MF, Hanif M, Ranjha M (2016) Methods of synthesis of hydrogels... a review. Saudi Pharm J 24:554-559. https://doi. org/10.1016/j.jsps.2015.03.022

Aksu Z (2005) Application of biosorption for the removal of organic pollutants: a review. Process Biochem 40:997-1026. https://doi. org/10.1016/j.procbio.2004.04.008

Alaba PA, Oladoja NA, Sani YM, Ayodele OB, Mohammed IY, Olupinla Sunday Felix, Daud WMW (2018) Insight into wastewater decontamination using polymeric adsorbents. J Environ Chem Eng 6:1651-1672. https://doi.org/10.1016/j. jece.2018.02.019

Al-Duri B (1996) Adsorption modeling and mass transfer. In: McKay G (ed) Use of adsorbents for the removal of pollutants from wastewaters, chapter 7. CRC Press, Boca Raton, pp 133-173

Ali I (2012) New generation adsorbents for water treatment. Chem Rev 112:5073-5091. https://doi.org/10.1021/cr300133d

Allen SJ (1996) Types of adsorbent materials. In: McKay G (ed) Use of adsorbents for the removal of pollutants from wastewaters, chapter 5. CRC Press, Boca Raton, pp 59-97

Al-Mubaddel FS, Haider S, Aijaz MO, Haider A, Kamal T, Almasry WA, Javid M, Khan SUD (2017) Preparation of the chitosan/ polyacrylonitrile semi-IPN hydrogel via glutaraldehyde vapors for the removal of Rhodamine B dye. Polym Bull 74:1535-1551. https://doi.org/10.1007/s00289-016-1788-y

Aly RO (2017) Implementation of chitosan inductively modified by gamma-rays copolymerization with acrylamide in the decontamination of aqueous basic dye solution. Arab J Chem 10:S121S126. https://doi.org/10.1016/j.arabjc.2012.06.017

Aminabhavi TM, Dharupaneedi SP (2017) Production of chitosanbased hydrogels for biomedical applications. In: Jennings JA, Bumgardner JD (eds) Chitosan based biomaterials. Volume 1: fundamentals, part III, chapter 12, vol 122. Woodhead publishing series in biomaterials. Elsevier, Kidlington, pp 295-319. https:// doi.org/10.1016/b978-0-08-100230-8.00012-1

Anastopoulos I, Bhatnagar A, Bikiaris DN, Kyzas GZ (2017) Chitin adsorbents for toxic metals: a review. Int J Mol Sci 18:1-11. https ://doi.org/10.3390/ijms18010114

Anjaneyulu Y, Sreedhara Chary N, Samuel Suman Raj D (2005) Decolourization of industrial effluents-available methods and emerging technologies: a review. Rev Environ Sci Bio/Technol. 4:245-273. https://doi.org/10.1007/s11157-005-1246-z

Arfin T (2017) Chitosan and its derivatives: overview of commercial applications in diverse fields. In: Ahmed S, Ikram S (eds) Chitosan-derivatives, composites and applications, chapter 5. Scrivener Publishing LLC, Beverly, pp 115-150. https://doi. org/10.1002/9781119364849.ch5

Azarova YA, Pestov AV, Bratskaya SZ (2016) Application of chitosan and its derivatives for solid-phase extraction of metal and metalloid ions: a mini-review. Cellulose 23:2273-2289. https ://doi.org/10.1007/s10570-016-0962-6
Barakat MA (2011) New trends in removing heavy metals from industrial wastewater. Arab J Chem 4:361-377. https://doi. org/10.1016/j.arabjc.2010.07.019

Barbusinski K, Salwiczek S, Paszewska A (2016) The use of chitosan for removing selected pollutants from water and wastewatershort review. Archit Civ Eng Environ 9:107-115

Berefield LD, Judkins JF, Weand BL (1982) Process chemistry for water and wastewater treatment. Prentice-Hall, New-Jersey, p 510

Bernardi F, Zadinelo IW, Alves HJ, Meurer F, dos Santos LD (2018) Chitins and chitosans for the removal of total ammoniac of aquaculture effluents. Aquaculture 483:203-212. https://doi. org/10.1016/j.aquaculture.2017.10.027

Bhatnagar A, Minocha AK (2006) Conventional and non-conventional adsorbents for removal of pollutants from water-a review. Indian J Chem Technol 13:203-217

Bhatnagar A, Sillanpää M (2009) Applications of chitin- and chitosan-derivatives for the detoxification of water and wastewater-a short review. Adv Colloid Int Sci 152:26-38. https://doi. org/10.1016/j.cis.2009.09.003

Blackburn RS (2004) Natural polysaccharides and their interactions with dye molecules: applications in effluent treatment. Environ Sci Technol 38:4905-4909. https://doi.org/10.1021/es049972n

Boamah PO, Huang Y, Hua M, Zhang Q, Wu J, Onumah J, Sam-Amoah LK, Boamah PO (2015) Sorption of heavy metal ions onto carboxylate chitosan derivatives-a mini-review. Ecotox Environ Saf 116:113-120. https://doi.org/10.1016/j.ecoenv.2015.01.012

Bratby J (ed) (2006) Coagulation and flocculation in water and wastewater treatment. IWA Publishing, London, p 407

Caccavo D, Cascone S, Lamberti G, Barba AA (2018) Hydrogels: experimental characterization and mathematical modelling or their mechanical and diffuse behavior. Chem Soc Rev 47:23572373. https://doi.org/10.1039/c7cs00638a

Chuah TG, Jumasiah A, Azni I, Katayon S, Choong SYT (2005) Rice husk as a potentially low-cost biosorbent for heavy metal and dye removal: an overview. Desalination 175:305-316. https:// doi.org/10.1016/j.desal.2004.10.014

Cooney DO (ed) (1999) Adsorption design for wastewater treatment. Lewis Publishers, Boca Raton, p 208

Copello GJ, Villanueva ME, Gonzalez JA, Lopez Eguees S, Diaz LE (2014) TEOS as an improved alternative for chitosan beads cross-linking: a comparative adsorption study. J Appl Polym Sci 131:41005. https://doi.org/10.1002/app.41005

Cox M, Négré P, Yurramendi L (2007) Industrial liquid effluents. INASMET Tecnalia, San Sebastian, p 283

Crini G (2005) Recent developments in polysaccharide-based materials used as adsorbents in wastewater treatment. Prog Polym Sci 30:38-70. https://doi.org/10.1016/j.progpolymsci.2004.11.002

Crini G (2006) Non-conventional low-cost adsorbents for dye removal. Bioresour Technol 97:1061-1085. https://doi.org/10.1016/j.biort ech.2005.05.001

Crini G (2015) Non-conventional adsorbents for dye removal. In: Sharma SK (ed) Green chemistry for dyes removal from wastewater. Scrivener Publishing LLC, Beverly, pp 359-407

Crini G, Badot PM (2008) Application of chitosan, a natural aminopolysaccharide, for dye removal from aqueous solutions by adsorption processes using batch studies: a review of recent literature. Prog Polym Sci 33:399-447. https://doi.org/10.1016/j. progpolymsci.2007.11.001

Crini G, Lichtfouse E (eds) (2018) Green adsorbents for pollutant removal-innovative materials. Environmental chemistry for a sustainable world. Springer, Basel, p 399. https://doi. org/10.1007/978-3-319-92162-4

Crini G, Badot PM, Guibal E (eds) (2009) Chitine et chitosane-du biopolymère à l'application. PUFC, France, Besançon, p 303

Crini G, Morin-Crini N, Fatin-Rouge N, Déon S, Fievet P (2017) Metal removal from aqueous media by polymer-assisted ultrafiltration 
with chitosan. Arab J Chem 10:S3826-S3839. https://doi. org/10.1016/j.arabjc.2014.05.020

Crini G, Torri G, Lichtfouse É, Kyzas GZ, Wilson LD, Morin-Crini N (2019) Cross-linked chitosan hydrogels for dye removal. In: Crini G, Lichtfouse É (eds) Chitin and chitosan-applications in food, agriculture, pharmacy, medicine and wastewater treatment, vol 35. Sustainable agriculture reviews. Springer, Basel. https://doi. org/10.1007/978-3-030-16581-9_10

Czechowska-Biskup R, Wach RA, Stojek P, Kamińska M, Rosiak JM, Ulański P (2016) Synthesis of chitosan and carboxymethyl chitosan hydrogels by electron beam irradiation. Prog Chem Appl Chitin Deriv 21:27-45. https://doi.org/10.15259 /PCACD.21.03

Dash M, Piras AM, Chiellini F (2009) Chitosan-based beads for controlled release of proteins. In: Barbucci R (ed) Hydrogels-biological properties and applications. Springer, Milan, pp 111-120

de Alvarenga ES (2011) Characterization and properties of chitosan. In: Elnashar M (ed) Biotechnology of biopolymers, chapter 5. InTech, Rijeka, pp 91-108. https://doi.org/10.5772/17020

de Andrade JR, Oliveira MF, da Silva MGC, Vieira MGA (2018) Adsorption of pharmaceuticals from water and wastewater using nonconventional low-cost materials: a review. Ind Eng Chem Res 57:3103-3127. https://doi.org/10.1021/acs.iecr.7b05137

de Luna MS, Altobelli R, Gioiella L, Castaldo R, Scherillo G, Filippone $\mathrm{G}$ (2017a) Role of polymer network and gelation kinetics on the mechanical properties and adsorption capacity of chitosan hydrogels for dye removal. J Polym Sci Part B Polym Phys 55:1843-1849. https://doi.org/10.1002/polb.24436

de Luna MS, Castaldo R, Altobelli R, Gioiella L, Filippone G, Gentile G, Ambrogi V (2017b) Chitosan hydrogels embedding hypercrosslinked polymer particles as reusable broad-spectrum adsorbents for dye removal. Carbohydr Polym 177:347-354. https:// doi.org/10.1016/j.carbpol.2017.09.006

Desbrières J, Guibal E (2018) Chitosan for wastewater treatment. Polym Int 67:7-14. https://doi.org/10.1002/pi.5464

Dolatkhah A, Wilson LD (2016) Magnetite/polymer brush nanocomposites with switchable uptake behavior toward methylene blue. ACS Appl Mater Interfaces 8:5595-5607. https://doi. org/10.1021/acsami.5b11599

Dolatkhah A, Wilson LD (2018) Salt-responsive $\mathrm{Fe}_{3} \mathrm{O}_{4}$ nanocomposites and phase behavior in water. Langmuir 34:341-350. https:// doi.org/10.1021/acs.langmuir.7b03613

Dragan ES (2014) Design and applications of interpenetrating polymer network hydrogels. A review. Chem Eng J 243:572-590. https:// doi.org/10.1016/j.cej.2014.01.065

Drăgan ES, Lazăr MM, Dinu MV, Doroftei F (2012) Macroporous composite IPN hydrogels based on poly(acrylamide) and chitosan with tuned swelling and sorption of cationic dyes. Chem Eng J 204-206: 198-209

Du WL, Xu ZR, Han XY, Xu YL, Miao ZG (2008) Preparation, characterization and adsorption properties of chitosan nanoparticles for eosin Y as a model anionic dye. J Hazard Mat 153:152-156

El Halah A, López-Carrasquero F, Contreras J (2018) Applications of hydrogels in the adsorption of metallic ions. Rev Cienc Ing 39:57-70

El-Harby NF, Ibrahim SMA, Mohamed NA (2017) Adsorption of Congo red dye onto antimicrobial terephthaloyl thiourea crosslinked chitosan hydrogels. Water Sci Technol 76:2719-2732. https://doi.org/10.2166/wst.2017.442

El-Sayed MM, Al Bazedi GA, Abdel-Fatah MA (2017) Development of a novel hydrogel adsorbent for removal of reactive dyes from textile effluents. Res J Pharm Biol Chem Sci 8:945-955

Elwakeel KZ (2010) Environmental application of chitosan resins for the treatment of water and wastewater: a review. J Dispers Sci Technol 31:273-288. https://doi.org/10.1080/01932690903167178
Esquerdo VM, Cadaval TRS Jr, Dotto GL, Pinto LAA (2014) Chitosan scaffold as an alternative adsorbent for the removal of hazardous food dyes from aqueous solutions. J Colloid Int Sci 424:7-15

Esquerdo VM, Quintana TM, Dotto GL, Pinto LA (2015) Kinetics and mass transfer aspects about the adsorption of tartrazine by a porous chitosan sponge. React Kinet Mech Catal 116:105-117. https://doi.org/10.1007/s11144-015-0893-5

Fan L, Zhang Y, Luo C, Lu F, Qiu H, Sun M (2012) Synthesis and characterization of magnetic \& \#x03B2;-cyclodextrin-chitosan nanoparticles as nano-adsorbents for removal of methyl blue. Int J Biol Macromol 50:444-450

Filipkowska U, Kuczajowska-Zadrożna M, Jóźwiak T, Szymczyk P, Nierobisz M (2016) Impact of chitosan cross-linking on RB 5 dye adsorption efficiency. Prog Chem Appl Chitin Deriv 21:4654. https://doi.org/10.15259/PCACD.21.04

Forgacs E, Cserhati T, Oros G (2004) Removal of synthetic dyes from wastewaters: a review. Environ Int 30:953-971. https://doi. org/10.1016/j.envint.2004.02.001

Gadd GM (2009) Biosorption: critical review of scientific rationale, environmental importance and significance for pollution treatment. J Chem Technol Biotechnol 84:13-28. https://doi. org/10.1002/jctb.1999

Gavrilescu M (2004) Removal of heavy metals from the environment by biosorption. Eng Life Sci 4:219-232. https://doi.org/10.1002/ elsc. 200420026

Gérente C, Lee VKC, Le Cloirec P, McKay G (2007) Application of chitosan for the removal of metals from wastewaters by adsorption-mechanisms and models review. Crit Rev Environ Sci Technol 37:41-127. https://doi.org/10.1080/106433806007290 89

Gonçalves JO, Dotto GL, Pinto LAA (2015) Cyanoguanidinecrosslinked chitosan to adsorption of food dyes in the aqueous binary system. J Mol Liq 211:425-430. https://doi.org/10.1016/j. molliq.2015.07.061

Gonçalves JO, Santos JP, Rios EC, Crispim MM, Dotto GL, Pinto LAA (2017) Development of chitosan based hybrid hydrogels for dyes removal from aqueous binary system. J Mol Liq 225:265-270. https://doi.org/10.1016/j.molliq.2016.11.067

Goosen MFA (ed) (1997) Applications of chitin and chitosan. CRC Press LLC, Boca Raton

Guo R, Wilson LD (2012) Synthetically engineered chitosan-based materials and their sorption properties with methylene blue in aqueous solution. J Colloid Int Sci 388:225-234. https://doi. org/10.1016/j.jcis.2012.08.010

Gupta VK, Suhas (2009) Application of low-cost adsorbents for dye removal - a review. J Environ Manag 90:2313-2342. https://doi. org/10.1016/j.jenvman.2008.11.017

Gupta VK, Nayak A, Agarwal S (2015) Bioadsorbents for remediation of heavy metals: current status and their future prospects. Environ Eng Res 20:1-18. https://doi.org/10.4491/eer.2014.018

Hadi P, Xu M, Ning C, Sze Ki Lin C, McKay G (2015) A critical review on preparation, characterization and utilization of sludgederived activated carbons for wastewater treatment. Chem Eng J 260:895-906. https://doi.org/10.1016/j.cej.2014.08.088

Hai FI, Yamamoto K, Fukushi K (2007) Hybrid treatment systems for dye wastewater. Crit Rev Environ Sci Technol 37:315-377. https ://doi.org/10.1080/10643380601174723

Hamdaoui O, Naffrechoux E (2007a) Modeling of adsorption isotherms of phenol and chlorophenols onto granular activated carbon. Part I. Two-parameter models and equations allowing determination of thermodynamic parameters. J Hazard Mater 147:381-394. https://doi.org/10.1016/j.hazmat.2007.01.021

Hamdaoui O, Naffrechoux E (2007b) Modeling of adsorption isotherms of phenol and chlorophenols onto granular activated carbon. Part II. Models with more than two parameters. J 
Hazard Mater 147:401-411. https://doi.org/10.1016/j.hazma t.2007.01.023

Henze M (ed) (2001) Wastewater treatment—biological and chemical processes. Springer, Berlin

Hirano S (1997) Applications of chitin and chitosan in the ecological and environmental fields. In: Goosen MFA (ed) Applications of chitin and chitosan, chapter 2. CRC Press LLC, Boca Raton, pp 31-56

Ho YS (2006) Review of second-order models for adsorption systems. J Hazard Mater 136:681-689. https://doi.org/10.1016/j.jhazm at.2005.12.043

Ho YS, McKay G (1998) A comparison of chemisorption kinetic models applied to pollutant removal on various sorbents. Process Saf Environ Prot 76:332-340

Honarkar H, Barikani M (2009) Applications of biopolymers I: chitosan. Monatsh Chem 140:1403-1420. https://doi.org/10.1007/ s00706-009-0197-4

Hou H, Zhou R, Wu P, Wu L (2012) Removal of Congo red dye from aqueous solution with hydroxyapatite/chitosan composite. Chem Eng J 211:336-342

Houghton JI, Quarmby J (1999) Biopolymers in wastewater treatment. Curr Opin Biotechnol 10:259-262. https://doi.org/10.1016/ S0958-1669(99)80045-7

Jing G, Wang L, Yu H, Amer WA, Zhang L (2013) Recent progress on study of hybrid hydrogels for water treatment. Coll Surf A Physicochem Eng Asp 416:86-94. https://doi.org/10.1016/j.colsu rfa.2012.09.043

Jóźwiak T, Filipkowska U, Rodziewicz J, Nowosad E (2013) Effect of cross-linking with glutaraldehyde on adsorption capacity of chitosan beads. Progress Chem Appl Chitin Deriv XVIII:35-47

Jóźwiak T, Filipkowska U, Szymczyk P, Kuczajowska-Zadrożna M, Mielcarek A (2015) Application of chitosan ionically crosslinked with sodium edetate for reactive dyes removal from aqueous solutions. Progress Chem Appl Chitin Deriv 20:82-96. https:// doi.org/10.15259/pcacd.20.08

Jóźwiak T, Filipkowska U, Szymczyk P, Zyśk M (2017a) Effect of the form and deacetylation degree of chitosan sorbents on sorption effectiveness of reactive black 5 from aqueous solutions. Int $\mathbf{J}$ Biol Macromol 95:1169-1178. https://doi.org/10.1016/j.ijbio mac.2016.11.007

Jóźwiak T, Filipkowska U, Szymczyk P, Rodziewicz J, Mielcarek A (2017b) Effect of ionic and covalent crosslinking agents on properties of chitosan beads and sorption effectiveness of reactive black 5 dye. React Funct Polym 114:58-74. https://doi. org/10.1016/j.reactfunctpolym.2017.03.007

Kanmani P, Aravind J, Kamaraj M, Sureshbabu P, Karthikeyan S (2017) Environmental applications of chitosan and cellulosic biopolymers: a comprehensive outlook. Bioresour Technol 242:295-303. https://doi.org/10.1016/j.biortech.2017.03.119

Karimi AR, Rostaminezhad B, Khodadadi A (2018) Effective removal of a cobalt-tetrasulfonated phthalocyanine dye from an aqueous solution with a novel modified chitosan-based superabsorbent hydrogel. J Appl Polym Sci 355:46167. https://doi.org/10.1002/ app. 46167

Karimifard S, Moghaddam MRA (2018) Application of response surface methodology in physicochemical removal of dyes from wastewater: a critical review. Sci Total Environ 640-641:772797. https://doi.org/10.1016/j.scitotenv.2018.05.355

Karoyo AH, Dehabadi L, Wilson LD (2018) Renewable starch particle carriers with switchable adsorption properties. ACS Sustain Chem Eng 6:4603-4613. https://doi.org/10.1021/acssuschem eng. $7 \mathrm{~b} 03345$

Katheresan V, Kansedo J, Lau SY (2018) Efficiency of various recent wastewater dye removal methods: a review. J Environ Chem Eng 6:4676-4697. https://doi.org/10.1016/j.jece.2018.06.060
Khalaf MN (ed) (2016) Green polymers and environmental pollution control. CRC Press; Apple Academic Press Inc, Oakville, p 436

Khan M, Lo IMC (2016) A holistic review of hydrogel applications in the adsorptive removal of aqueous pollutants: recent progress, challenges, and perspectives. Water Res 106:259-271. https:// doi.org/10.1016/j.watres.2016.10.008

Khor E, Wan ACA (2014) Overview of chitin and chitosan research. In: Khor E, Wan ACA (eds) Chitin: fulfilling a biomaterials promise, chapter 1. Elsevier, Oxford, pp 1-20

Kos L (2016) Use of chitosan for textile wastewater decolourization. Fibres Text 24:130-135. https://doi.org/10.5604/12303 666.1196623

Kurita K (1998) Chemistry and application of chitin and chitosan. Polym Degrad Stab 59:117-120

Kurita K (2006) Chitin and chitosan: functional biopolymers from marine crustaceans. Mar Biotechnol 8:203-226. https://doi. org/10.1007/s10126-005-0097-5

Kuroiwa T, Takada H, Shogen A, Saito K, Kobayashi I, Uemura K, Kanazawa A (2017) Cross-linkable chitosan-based hydrogel microbeads with $\mathrm{pH}$-responsive adsorption properties for organic dyes prepared using size-tunable microchannel emulsification technique. Coll Surf A Physicochem Eng Asp 514:69-78. https ://doi.org/10.1016/j.colsurfa.2016.11.046

Kyzas GZ, Bikiaris DN (2015) Recent modifications of chitosan for adsorption applications: a critical and systematic review. Mar Drugs 13:312-337. https://doi.org/10.3390/md13010312

Kyzas GZ, Kostoglou M (2014) Green adsorbents for wastewaters: a critical review. Materials 7:333-364. https://doi.org/10.3390/ ma7010333

Kyzas GZ, Fu J, Matis KA (2013a) The change from past to future for adsorbent materials in treatment of dyeing wastewaters. Materials 6:5131-5158. https://doi.org/10.3390/ma6115131

Kyzas GZ, Kostoglou M, Lazaridis NK, Bikiaris DN (2013b) Decolorization of dyeing wastewater using polymeric adsorbentsan overview. In: Günay M (ed) Eco-friendly textile dyeing and finishing, chapter 7. InTech, Rijeka, pp 177-205. https://doi. org/10.5772/52817

Kyzas GZ, Lazaridis NK, Kostoglou M (2014) Adsorption/desorption of a dye by a chitosan derivative: experiments and phenomenological modeling. Chem Eng J 248:327-336. https://doi. org/10.1016/j.cej.2014.03.063

Kyzas GZ, Bikiaris DN, Mitropoulos AC (2017) Chitosan adsorbents for dye removal: a review. Polym Int 66:1800-1811. https://doi. org/10.1002/pi.5467

Langmuir I (1916) The constitution and fundamental properties of solids and liquids. Part I. Solids. J Am Chem Soc 38:2221-2295

Langmuir I (1918) The adsorption of gases on plane surfaces of glass, mica and platinum. J Am Chem Soc 40:1361-1403

Lee KE, Morad N, Teng TT, Poh BT (2012) Development, characterization and the application of hybrid materials in coagulation/ flocculation of wastewater: a review. Chem Eng J 203:370-386. https://doi.org/10.1016/j.cej.2012.06.109

Lee CS, Robinson J, Chong MF (2014) A review on application of flocculants in wastewater treatment. Proc Saf Environ Protection 92:489-508. https://doi.org/10.1016/j.psep.2014.04.010

Li CB, Hein S, Wang K (2008) Biosorption of chitin and chitosan. Mater Sci Technol 24:1088-1099. https://doi.org/10.1179/17438 408X341771

Li DK, Li Q, Mao DY, Bai NN, Dong HZ (2017) A versatile biobased material for efficiently removing toxic dyes, heavy metal ions and emulsified oil droplets from water simultaneously. Bioresour Technol 245:649-655. https://doi.org/10.1016/j.biort ech.2017.09.016

Lin CY, Li SX, Chen M, Jiang R (2017) Removal of Congo red dye by gemini surfactant $\mathrm{C}$-12-4-C-12 center dot $2 \mathrm{Br}$-modified chitosan 
hydrogel beads. J Dispers Sci Technol 38:46-57. https://doi. org/10.1080/01932691.2016.1138229

Liu C, Bai R (2014) Recent advances in chitosan and its derivatives as adsorbents for removal of pollutants from water and wastewater. Curr Opin Chem Eng 4:62-70. https://doi.org/10.1016/j.coche .2014.01.004

Liu DHF, Liptak BG (eds) (2000) Wastewater treatment. CRC Press, Boca Raton

Liu Y, Huang SB, Zhao YS, Zhang YQ (2018) Fabrication of threedimensional porous beta-cyclodextrin/chitosan functionalized graphene oxide hydrogel for methylene blue removal from aqueous solution. Coll Surf A Physicochem Eng Asp 539:1-10. https ://doi.org/10.1016/j.colsurfa.2017.11.066

Luna-Bárcenas G, Prokhorov E, Elizalde-Peña E, Nuno-Licona A, Sanchez IC, Gough JE, Velasquillo-Martinez C, Schmidt CE (2011) Chitosan-based hydrogels for tissue engineering applications. Series: biotechnology in agriculture, industry and medicine chemical engineering methods and technology. Nova Science Publishers, New York

Mandal B, Ray SK (2014) Swelling, diffusion, network parameters and adsorption properties of IPN hydrogel of chitosan and acrylic copolymer. Mater Sci Eng C Mater Biol Appl 44:132-143. https ://doi.org/10.1016/j.msec.2014.08.021

Melo BC, Paulino FAA, Cardoso VA, Pereira AGB, Fajardo AR, Rodrigues FHA (2018) Cellulose nanowhiskers improve the methylene blue adsorption capacity of chitosan- $g$-poly(acrylic acid) hydrogel. Carbohydr Polym 181:358-367. https://doi. org/10.1016/j.carbpol.2017.10.079

Michalak I, Chojnacka K, Witek-Krowiak A (2013) State of the art for the biosorption process-a review. Appl Biochem Biotechnol. https://doi.org/10.1007/s12010-013-0269-0

Miretzky P, Cirelli AF (2011) Fluoride removal from water by chitosan derivatives and composites: a review. J Fluor Chem 132:231240. https://doi.org/10.1016/j.jfluchem.2011.02.001

Mittal H, Ray SS, Okamoto M (2016) Recent progress on the design and applications of polysaccharide-based graft copolymer hydrogels as adsorbents for wastewater purification. Macromol Mater Eng 301:496-522. https://doi.org/10.1002/mame.201500399

Mohamed MH, Udoetok IA, Wilson LD, Headley JV (2015) Fractionation of carboxylate anions from aqueous solution using chitosan cross-linked sorbent materials. RSC Adv 5:82065-82077. https ://doi.org/10.1039/C5RA13981C

Mohan D, Pittman CU (2007) Arsenic removal from waste/wastewater using adsorbents - a critical review. J Hazard Mater 142:1-53. https://doi.org/10.1016/j.jhazmat.2007.01.006

Momenzadeh H, Tehrani-Bagha AR, Khosravi A, Gharanjig K, Holmberg K (2011) Reactive dye removal from wastewater using a chitosan nanodispersion. Desalination 271:225-230

Morin-Crini N, Crini G (eds) (2017) Eaux industrielles contaminées. PUFC, Besançon, p 513

Morin-Crini N, Lichtfouse É, Torri G, Crini G (2019) Fundamentals and applications of chitosan. In: Crini G, Lichtfouse É (eds) Chitin and chitosan-history, fundamentals \& innovations, chapter 2, vol 35. Sustainable agriculture reviews. Springer, Basel. https://doi.org/10.1007/978-3-030-16538-3_2

Mozalewska V, Czechowska-Biskup R, Olejnik AK, Wach RA, Ulanski P, Rosiak JM (2017) Chitosan-containing hydrogel wound dressings prepared by radiation technique. Radiat Phys Chem 134:1-7. https://doi.org/10.1016/j.radphyschem.2017.01.003

Muya FN, Sunday CE, Baker P, Iwuoha E (2016) Environmental remediation of heavy metal ions from aqueous solution through hydrogel adsorption: a critical review. Water Sci Technol 73:983-992. https://doi.org/10.2166/wst.2015.567
Muzzarelli RAA (2011) Potential of chitin/chitosan-bearing materials for uranium recovery: an interdisciplinary review. Carbohydr Polym 84:54-63. https://doi.org/10.1016/j.carbpol.2010.12.025

Nakhjiri MT, Marandi GB, Kurdtabar M (2018) Poly(AA-co-VPA) hydrogel cross-linked with $\mathrm{N}$-maleyl chitosan as dye adsorbent: isotherms, kinetics and thermodynamic investigation. Int J Biol Macromol 117:152-166. https://doi.org/10.1016/j.jibiomac.2018.05.140

Nasef MM, Nallappan M, Ujang Z (2014) Polymer-based chelating adsorbents for the selective removal of boron from water and wastewater: a review. React Funct Polym 85:54-68. https://doi. org/10.1016/j.reactfunctpolym.2014.10.007

Nechita P (2017) Applications of chitosan in wastewater treatment. In: Shalaby EA (ed) Biological activities and application of marine polysaccharides, chapter 10. InTech, Rijeka, pp 209-228. https ://doi.org/10.5772/65289

Nilsen-Nygaard J, Strand SP, Vårum KJ, Draget KI, Nordgård CT (2015) Chitosan: gels and interfacial properties. Polymers 7:552579. https://doi.org/10.3390/polym7030552

No HK, Meyers SP (1995) Preparation and characterization of chitin and chitosan-a review. J Aquat Food Prod Technol 4:27-52. https://doi.org/10.1300/J030v04n02_03

No HK, Meyers SP (2000) Application of chitosan for treatment of wastewaters. Rev Environ Contam Toxicol 63:1-28. https://doi. org/10.1007/978-1-4757-6429-1_1

Oladoja NA (2015) Headway on natural polymeric coagulants in water and wastewater treatment operations. J Water Proc Eng 6:174192. https://doi.org/10.1016/j.jwpe.2015.04.004

Oliveira LS, Franca AS (2008) Low cost adsorbents from agro-food wastes. In: Greco LV, Bruno MN (eds) Food science and technology: new research. Nova Publishers, New-York, pp 1-39

Olivera S, Muralidhara HB, Venkatesh K, Guna VK, Gopalakrishna K, Kumar KY (2016) Potential applications of cellulose and chitosan nanoparticles/composites in wastewater treatment: a review. Carbohydr Polym 153:600-618. https://doi.org/10.1016/j. carbpol.2016.08.017

Onsoyen E, Skaugrud O (1990) Metal recovery using chitosan. J Chem Technol Biotechnol 49:395-404

Pakdel PR, Peighambardoust SJ (2018) Review on recent progress in chitosan-based hydrogels for wastewater treatment application. Carbohydr Polym 201:264-279. https://doi.org/10.1016/j.carbp ol.2018.08.070

Park D, Yun YS, Park JM (2010) The past, present, and future trends of biosorption. Biotechnol Bioprocess Eng 15:86-102. https:// doi.org/10.1007/s12257-009-0199-4

Pellá MCG, Lima-Tenorio MK, Tenorio-Neto ET, Guilherme MR, Muniz EC, Rubira AF (2018) Chitosan-based hydrogels: from preparation to biomedical applications. Carbohydr Polym 196:233-245. https://doi.org/10.1016/j.carbpol.2018.05.033

Pereira AGB, Martins AF, Paulino AT, Fajardo AR, Guilherme MR, Faria MGI, Linde GA, Rubira AF, Muniz EC (2017) Recent advances in designing hydrogels from chitin and chitin-derivatives and their impact on environment and agriculture: a review. Rev Virtual Quim 9:370-386. https://doi.org/10.21577/19846835.20170021

Peters MG (1995) Applications and environmental aspects of chitin and chitosan. J Mat Sci Pure Appl Chem A32:629-640

Piaskowski K, Swiderska-Dabrowska R, Zarzycki PK (2018) Dye removal from water and wastewater using various physical, chemical, and biological processes. J AOAC Int 101:1371-1384. https://doi.org/10.5740/jaoacint.18-0051

Piątkowski M, Janus Ł, Radwan-Pragłowska J, Raclavsky K (2017) Microwave-enhanced synthesis of biodegradable multifunctional chitosan hydrogels for wastewater treatment. Express Polym Lett 11:809-819. https://doi.org/10.3144/expresspolymlett.2017.77 
Pillai CKS, Paul W, Sharma CP (2009) Chitin and chitosan polymers: chemistry, solubility and fiber formation. Prog Polym Sci 34:641-678. https://doi.org/10.1016/j.progpolymsci.2009.04.001

Pokhrel D, Viraraghavan T (2004) Treatment of pulp and paper mill wastewater-a review. Sci Total Technol 333:37-58. https://doi. org/10.1016/j.scitotenv.2004.05.017

Qi C, Zhao L, Lin Y, Wu D (2018) Graphene oxide/chitosan sponge as a novel filtering material for the removal of dye from water. J Colloid Int Sci 517:18-27. https://doi.org/10.1016/j.jcis.2018.01.089

Qu J (2008) Research progress of novel adsorption processes in water purification: a review. J Environ Sci 20:1-13. https://doi. org/10.1016/S1001-0742(08)60001-7

Ramakrishna KR, Viraraghavan T (1997) Dye removal using low cost adsorbents. Water Sci Technol 36:189-196. https://doi. org/10.1016/S0273-1223(97)00387-9

Rathoure AK, Dhatwalia VK (2016) Toxicity and waste management using bioremediation. IGI Global, Hershey, p 421

Ravi Kumar MNV (2000) A review of chitin and chitosan applications. React Funct Polym 46:1-27. https://doi.org/10.1016/S1381 $-5148(00) 00038-9$

Ravichandran YD, Rajesh R (2013) Marine polysaccharide (chitosan) and its derivatives as water purifier isolation and characterization of chitin and chitosan. In: Kim SK (ed) Marine biomaterials. Characterization, isolation and applications, part IV, chapter 38. CRC Press, Boca Raton, pp 747-764

Reddy DHK, Lee SM (2013) Application of magnetic chitosan composites for the removal of toxic metal and dyes from aqueous solutions. Adv Colloid Int Sci 201-202:68-93. https://doi. org/10.1016/j.cis.2013.10.002

Rhazi M, Tolaimate A, Habibi Y (2012) Interactions of chitosan with metals for water purification. In: Habibi Y, Lucia A (eds) polysaccharide building blocks: a sustainable approach to the development of renewable biomaterials, chapter 4. Wiley, New Jersey, pp 127-142

Roberts GAF (1992) Chitin chemistry, 1st edn. Macmillan Press, London

Sabzevari M, Cree DE, Wilson LD (2018) Graphene oxide-chitosan composite material for treatment of a model dye effluent. ACS Omega 32:1-10. https://doi.org/10.1021/acsomega.8b01871

Salehi R, Arami M, Mahmoodi NM, Bahrami H, Khorramfar S (2010) Novel biocompatible composite (chitosan-zinc oxide nanoparticle): preparation, characterization and dye adsorption properties. Coll Surf B Biointerfaces 80:86-93

Salehi E, Daraei P, Shamsabadi AA (2016) A review on chitosan-based adsorptive membranes. Carbohydr Polym 152:419-432. https:// doi.org/10.1016/j.carbpol.2016.07.033

Salehizadeh H, Yan N, Farnood R (2018) Recent advances in polysaccharide bio-based flocculants. Biotechnol Adv 36:92-119. https ://doi.org/10.1016/j.biotechadv.2017.10.002

Sandford P (1989) Chitosan: commercial uses and potential applications. In: Skjåk-Braek E, Anthonsen T, Standorf P (eds) Chitin and chitosan: sources chemistry, biochemistry, physical properties and applications. Elsevier Applied Science, London, pp $51-69$

Sanghi R, Verma P (2013) Decolorisation of aqueous dye solutions by low-cost adsorbents: a review. Coloration Technol 129:85-108. https://doi.org/10.1111/cote.12019

Shariatinia Z, Jalali AM (2018) Chitosan-based hydrogels: preparation, properties and applications. Int J Biol Macromol 115:194-220. https://doi.org/10.1016/j.ijbiomac.2018.04.034

Sharma SK (ed) (2015) Green chemistry for dyes removal from wastewater. Scrivener Publishing LLC Wiley, Beverley, p 496

Sharma SK, Sanghi R (eds) (2012) Advances in water treatment and pollution prevention. Dordrecht, Springer, p 457

Shen X, Shamshina JL, Berton P, Gurau G, Rogers RD (2016) Hydrogels based on cellulose and chitin: fabrication, properties, and applications. Green Chem 18:53-75. https://doi.org/10.1039/ $\mathrm{c} 5 \mathrm{gc} 02396 \mathrm{c}$

Shukla SK, Mishra AK, Arotiba OA, Mamba BB (2013) Chitosanbased nanomaterials: a state-of-the-art. Int J Biol Macromol 59:46-58. https://doi.org/10.1016/j.ijbiomac.2013.04.043

Sinha S, Singh R, Chaurasia AK, Nigam S (2016) Self-sustainable Chlorella pyrenoidosa strain NCIM 2738 based photobioreactor for removal of direct red-31 dye along with other industrial pollutants to improve the water-quality. J Hazard Mater 306:386394. https://doi.org/10.1016/j.jhazmat.2015.12.011

Skjåk-Braek G, Anthonsen T, Sandford PA (eds) (1989) Chitin and chitosan. Sources, chemistry, biochemistry, physical properties and applications. Elsevier Applied Science, New York

Subramani SE, Thinakaran N (2017) Isotherm, kinetic and thermodynamic studies on the adsorption behavior of textile dyes onto chitosan. Proc Saf Environ Prot 106:1-10. https://doi.org/10.1016/j. psep.2016.11.024

Sudha PN (2011) Chitin/chitosan and derivatives for wastewater treatment. In: Kim SK (ed) Chitin, chitosan, oligosaccharides and their derivatives: biological activities and applications, chapter 39. CRC Press, Boca Raton, pp 561-588

Sudha PN, Aisverya S, Gomathi T, Vijayalakshmi K, Saranya M, Sangeetha K, Latha S, Thomas S (2017) Applications of chitin/ chitosan and its derivatives as adsorbents, coagulants and flocculants. In: Ahmed S, Ikram S (eds) Chitosan-derivatives, composites and applications. Scrivener Publishing LLC, Beverly, pp 453-487. https://doi.org/10.1002/9781119364849.ch17

Tan KB, Vakili M, Horri BA, Poh PE, Abdullah AZ, Salamatinaia B (2015) Adsorption of dyes by nanomaterials: recent developments and adsorption mechanisms. Sep Purif Technol 150:229242. https://doi.org/10.1016/j.seppur.2015.07.009

Tang X, Zhang X, Zhou A (2007) Research progresses on adsorbing heavy metal ions with crosslinked chitosan. Ion Exch Sorpt 23:378-384

Teng D (2016) From chitin to chitosan. In: Yao K, Li J, Yao F, Yin $\mathrm{Y}$ (eds) chitosan-based hydrogels: functions and applications, chapter 1. CRC Press, Boca Raton, pp 1-38

Tran VS, Ngo HH, Guo W, Zhang J, Liang S, Ton-That C, Zhang $X$ (2015) Typical low cost biosorbents for adsorptive removal of specific organic pollutants from water. Bioresour Technol 182:353-363. https://doi.org/10.1016/j.biortech.2015.02.003

Udoetok IA, Wilson LD, Headley JV (2016) Self-assembled and crosslinked animal and plant-based polysaccharides: chitosan-cellulose composites and their anion uptake. ACS Appl Mater Interfaces 8:33197-33209. https://doi.org/10.1021/acsami.6b11504

Ujang Z, Diah M, Rashid AHA, Halim AS (2011) The development, characterization and application of water soluble chitosan. In: Elnashar M (ed) Biotechnology of biopolymers, chapter 6 . InTech, Rijeka, pp 109-130. https://doi.org/10.5772/16771

Ullah F, Othman MBH, Javed F, Ahmad Z, Md Akil H (2015) Classification, processing and application of hydrogels: a review. Mater Sci Eng C 57:414-433. https://doi.org/10.1016/j. msec.2015.07.053

Vakili M, Rafatullah M, Salamatinia B, Abdullah AZ, Ibrahim MH, Tan KB, Gholami Z, Amouzgar P (2014) Application of chitosan and its derivatives as adsorbents for dye removal from water and wastewater: a review. Carbohydr Polym 113:115-130. https:// doi.org/10.1016/j.carbpol.2014.07.007

Van Tran V, Park D, Lee YC (2018) Hydrogel applications for adsorption of contaminants in water and wastewater treatment. Environ Sci Pollut Res 25:24569-24599. https://doi.org/10.1007/s1135 6-018-2605-y

van Vliergerghe S, Dubruel P, Schacht E (2011) Biopolymer-based hydrogels as scaffolds for tissue engineering applications: a review. Biomacromol 12:1387-1408. https://doi.org/10.1021/ bm200083n 
Vandenbossche M, Jimenez M, Casetta M, Traisnel M (2015) Remediation of heavy metals by biomolecules: a review. Critical Rev Environ Sci Technol 45:1644-1704. https://doi. org/10.1080/10643389.2014.966425

Varma AJ, Deshpande SV, Kennedy JF (2004) Metal complexation by chitosan and its derivatives: a review. Carbohydr Polym 55:7793. https://doi.org/10.1016/j.carbpol.2003.08.005

Vaz MG, Pereira AGB, Fajardo AR, Azevedo ACN, Rodrigues FHA (2017) Methylene blue adsorption on chitosan-g-poly(acrylic acid)/rice husk ash superabsorbent composite: kinetics, equilibrium, and thermodynamics. Water Air Soil Pollut 228:14. https ://doi.org/10.1007/s11270-016-3185-4

Wang J, Chen C (2009) Biosorbents for heavy metals and their future. Biotechnol Adv 27:195-226. https://doi.org/10.1016/j.biotechadv .2008.11.002

Wang J, Zhuang S (2017) Removal of various pollutants from water and wastewater by modified chitosan adsorbents. Crit Rev Environ Sci Technol 47:2331-2386. https://doi.org/10.1080/10643 389.2017.1421845

Wang C, Li J, Yao F (2016) Application of chitosan-based biomaterials in tissue engineering. In: Yao K, Li J, Yao F, Yin Y (eds) Chitosan-based hydrogels: functions and applications, chapter 9. CRC Press, Boca Raton, pp 407-468

Wang WB, Zhang HX, Shen JF, Ye MX (2018) Facile preparation of magnetic chitosan/poly (vinyl alcohol) hydrogel beads with excellent adsorption ability via freezing-thawing method. Coll Surf A Physicochem Eng Asp 553:672-680. https://doi. org/10.1016/j.colsurfa.2018.05.094

Wilson LD, Tewari BB (2018) Chitosan-based adsorbents: environmental applications for the removal of arsenicals. Mater Res Found 34:133-160. https://doi.org/10.21741/9781945291753-7

Wojnárovits L, Takács E (2008) Irradiation treatment of azo dye containing wastewater: an overview. Rad Phys Chem 77:225-244. https://doi.org/10.1016/j.radphyschem.2007.05.003

Wong YC, Szeto YS, Cheung WH, McKay G (2003) Equilibrium studies for acid dye adsorption onto chitosan. Langmuir 19:7888-7894

Wong YC, Szeto YS, Cheung WH, McKay G (2004) Adsorption of acid dyes on chitosan - equilibrium isotherm analyses. Proc Biochem 39:693-702. https://doi.org/10.1016/S0032-9592(03)00152-3

Xiao Y, Zhu J, Zheng L (2016) Applications of chitosan-based gels in pharmaceuticals. In: Yao K, Li J, Yao F, Yin Y (eds) Chitosanbased hydrogels: functions and applications, chapter 7. CRC Press, Boca Raton, pp 315-338

Yang R, Li H, Huang M, Yang H, Li A (2016a) A review on chitosanbased flocculants and their applications in water treatment. Water Res 95:59-89. https://doi.org/10.1016/j.watres.2016.02.068
Yang H, Sheikhi A, van de Ven TGM (2016b) Reusable green aerogels from cross-linked hairy nanocrystalline cellulose and modified chitosan for dye removal. Langmuir 32:11771-11779. https://doi. org/10.1021/acs.langmuir.6b03084

Yao K, Li J, Yao F, Yin Y (eds) (2016) Chitosan-based hydrogels: functions and applications. CRC Press, Boca Raton, p 521

Yong SK, Shrivastava M, Srivastava P, Kunhikrishnan A, Bolan N (2015) Environmental applications of chitosan and its derivatives. In: Whitacre DM (ed) Book series: reviews of environmental contamination and toxicology, vol 233. Springer, Berlin, pp 1-43. https://doi.org/10.1007/978-3-319-10479-9_1

Zahir A, Aslam Z, Kamal MS, Ahmad W, Abbas A, Shawabkeh RA (2017) Development of novel cross-linked chitosan for the removal of anionic Congo red dye. J Mol Liq 244:211-218. https ://doi.org/10.1016/j.molliq.2017.09.006

Zhang M, Kohr E, Hirano S (1993) Hydrogels of chitin and chitosan. In: Nishinari K, Doi E (eds) Food hydrocolloids: structures, properties, and functions. Plenum Press, New York, pp 65-70

Zhang L, Zeng Y, Cheng Z (2016) Removal of heavy metal ions using chitosan and modified chitosan: a review. J Mol Liq 214:175191. https://doi.org/10.1016/j.molliq.2015.12.013

Zhao J (2016) Chitosan-based gels for the drug delivery system. In: Yao K, Li J, Yao F, Yin Y (eds) Chitosan-based hydrogels: functions and applications, chapter 6. CRC Press, Boca Raton, pp 263-314

Zhao S, Zhou F, Li L, Cao M, Zuo D, Liu H (2012) Removal of anionic dyes from aqueous solutions by adsorption of chitosanbased semi-IPN hydrogel composites. Compos Part B Eng 43:1570-1578

Zhou H, Xu LL, Wen YZ, Lin KD, Zeng XM (2017a) Ring-like structured chitosan-metal hydrogel: mass production, formation mechanism and applications. J Colloid Int Sci 490:233-241. https:// doi.org/10.1016/j.jcis.2016.11.066

Zhou JH, Hao BZ, Wang LB, Ma JZ, Cheng WJ (2017b) Preparation and characterization of nano- $\mathrm{TiO}_{2} /$ chitosan/poly(N-isopropylacrylamide) composite hydrogel and its application for removal of ionic dyes. Sep Purif Technol 176:196-199. https:// doi.org/10.1016/j.seppur.2016.11.069

Publisher's Note Springer Nature remains neutral with regard to jurisdictional claims in published maps and institutional affiliations. 